\title{
Structure/Function Studies of the $\alpha 4$ Subunit Reveal Evolutionary Loss of a GlyR Subtype Involved in Startle and Escape Responses
}

\author{
Sophie Leacock ${ }^{1 \dagger}$, Parnayan Syed ${ }^{2 \dagger}$, Victoria M. James ${ }^{1 \dagger}$, Anna Bode ${ }^{2}$, \\ Koichi Kawakami ${ }^{3}$, Angelo Keramidas ${ }^{2}$, Maximiliano Suster ${ }^{4 \ddagger}$, Joseph W. Lynch ${ }^{2,5}$ \\ and Robert J. Harvey ${ }^{6,7 *}$ \\ ${ }^{1}$ Department of Pharmacology, UCL School of Pharmacy, London, United Kingdom, ${ }^{2}$ Queensland Brain Institute, \\ The University of Queensland, Brisbane, QLD, Australia, ${ }^{3}$ Division of Molecular and Developmental Biology, National Institute \\ of Genetics and Department of Genetics, Graduate University for Advanced Studies (SOKENDAl), Mishima, Japan, \\ ${ }^{4}$ Neural Circuits and Behaviour Group, Uni Research AS, Bergen, Norway, ${ }^{5}$ School of Biomedical Sciences, The University \\ of Queensland, Brisbane, QLD, Australia, ${ }^{6}$ School of Health and Sport Sciences, University of the Sunshine Coast, \\ Sippy Downs, QLD, Australia, ${ }^{7}$ Sunshine Coast Health Institute, Birtinya, QLD, Australia
}

\section{OPEN ACCESS}

Edited by:

Hans-Georg Breitinger, German University in Cairo, Egypt

Reviewed by:

Marcus Semtner, Max Delbrück Center for Molecular Medicine (HZ), Germany Ralf Enz,

University of Erlangen-Nuremberg. Germany

Yoav Paas,

Bar-Ilan University, Israel

*Correspondence:

Robert J. Harvey

r.j.harvey@usc.edu.au

${ }^{t}$ These authors have contributed equally to this work.

${ }^{\ddagger}$ Present address: Maximiliano Suster, Allmyhomes $\mathrm{GmbH}$, Berlin, Germany

Received: 13 November 2017 Accepted: 16 January 2018 Published: 31 January 2018

Citation: Leacock S, Syed P, James VM, Bode A, Kawakami K, Keramidas A, Suster M, Lynch JW and Harvey RJ (2018) Structure/Function Studies of the a 4 Subunit Reveal Evolutionary Loss of a GlyR Subtype Involved in Startle and Escape Responses.

Front. Mol. Neurosci. 11:23. doi: 10.3389/fnmol.2018.00023
Inhibitory glycine receptors (GlyRs) are pentameric ligand-gated anion channels with major roles in startle disease/hyperekplexia (GlyR $\alpha 1$ ), cortical neuronal migration/autism spectrum disorder (GlyR $\alpha 2$ ), and inflammatory pain sensitization/rhythmic breathing (GlyR $\alpha 3$ ). However, the role of the GlyR $\alpha 4$ subunit has remained enigmatic, because the corresponding human gene (GLRA4) is thought to be a pseudogene due to an in-frame stop codon at position 390 within the fourth membrane-spanning domain (M4). Despite this, a recent genetic study has implicated GLRA4 in intellectual disability, behavioral problems and craniofacial anomalies. Analyzing data from sequenced genomes, we found that GlyR $\alpha 4$ subunit genes are predicted to be intact and functional in the majority of vertebrate species - with the exception of humans. Cloning of human GlyR a4 cDNAs excluded alternative splicing and RNA editing as mechanisms for restoring a full-length GlyR a 4 subunit. Moreover, artificial restoration of the missing conserved arginine (R390) in the human cDNA was not sufficient to restore GlyR $\alpha 4$ function. Further bioinformatic and mutagenesis analysis revealed an additional damaging substitution at K59 that ablates human GlyR $\alpha 4$ function, which is not present in other vertebrate GlyR $\alpha 4$ sequences. The substitutions K59 and X390 were also present in the genome of an ancient Denisovan individual, indicating that GLRA4 has been a pseudogene for at least 30,000-50,000 years. In artificial synapses, we found that both mouse and gorilla $\alpha 4 \beta$ GlyRs mediate synaptic currents with unusually slow decay kinetics. Lastly, to gain insights into the biological role of GlyR $\alpha 4$ function, we studied the duplicated genes glra4a and glra $4 b$ in zebrafish. While glra $4 b$ expression is restricted to the retina, using a novel tol2-GAL4FF gene trap line (SAIGFF16B), we found that the zebrafish GlyR $\alpha 4 a$ subunit gene ( $g$ /ra4a) is strongly expressed in spinal cord and hindbrain commissural neurones. Using gene knockdown and a dominant-negative GlyR $\alpha 4 \mathrm{a}^{\mathrm{R} 278 \mathrm{Q}}$ mutant, we found that GlyR a4a contributes to touch-evoked escape behaviors in zebrafish. Thus, although GlyR $\alpha 4$ is unlikely to be involved in human startle responses or disease states, this subtype may contribute to escape behaviors in other organisms. 


\section{INTRODUCTION}

Inhibitory glycine receptors (GlyRs) are ligand-gated anion channels, consisting of pentameric combinations of GlyR $\alpha$ and $\beta$ subunits. There are five known GlyR subtypes (containing $\alpha 1$, $\alpha 2, \alpha 3$ or $\alpha 4$ subunits together with the GlyR $\beta$ subunit) that are differentially expressed in developing brain and adult spinal cord, hindbrain, cerebellum and retina. Mutations in GLRA1 and GLRB, encoding the GlyR $\alpha 1$ and $\beta$ subunits, cause startle disease/hyperekplexia, a neurological disorder characterized by noise- or touch-induced seizures in neonates (Shiang et al., 1993; Rees et al., 2002; Chung et al., 2010, 2013; James et al., 2013). Allelic variants of GLRB may also contribute to the risk of panic disorder by increasing startle responses and thus agoraphobic cognitions (Deckert et al., 2017). However, the biological roles of other GlyR subtypes, containing the $\alpha 2, \alpha 3$ and $\alpha 4$ subunits, are still under investigation. Knockout mice have revealed roles for GlyR $\alpha 2$ in retinal rod photoreceptor development, crossover inhibition and the receptive field surround of "off" retinal ganglion cells (Young and Cepko, 2004; Nobles et al., 2012; Zhang C. et al., 2015). GlyR $\alpha 2$ also appears to modulate ethanol consumption, since knockout mice show reduced ethanol intake and preference in the two-bottle choice test (Blednov et al., 2015). Most recently, GlyR $\alpha 2$ has been shown to control cortical neuronal progenitor homeostasis, migration and circuit formation (Avila et al., 2013, 2014; Morelli et al., 2017) with mild microcephaly (Avila et al., 2014), susceptibility to seizures (Morelli et al., 2017) and deficits in long-term potentiation and object recognition memory (Pilorge et al., 2016) observed in Glra2 knockout mice. Consistent with these findings, loss of function mutations in the human GlyR $\alpha 2$ subunit gene (GLRA2) have been reported in cases of autism spectrum disorder, with additional features in some cases such as language delay and seizures (Pinto et al., 2010; Piton et al., 2011; Iossifov et al., 2014; Pilorge et al., 2016). By contrast, the generation of GlyR a3 subunit knockout mice and subtype specific antibodies revealed that this subtype is abundant in the spinal cord dorsal horn, where it plays a key role in central inflammatory pain sensitization (Harvey et al., 2004, 2009; Hösl et al., 2006). This has led to significant interest in GlyR $\alpha 3$ as a target for novel analgesics (Harvey et al., 2004; Xiong et al., 2011; Balansa et al., 2013; Han et al., 2013; Acuña et al., 2016; Stead et al., 2016; Huang et al., 2017). However, it is important to note that GlyR $\alpha 3$ also has other biological roles. For example, a 5-HTR $\mathrm{AA}^{-}$ GlyR $\alpha 3$ signaling pathway controls rhythmic breathing in the brainstem pre-Bötzinger complex (Manzke et al., 2010), with disruption of this pathway in GlyR $\alpha 3$ knockout mice resulting in an irregular respiratory rhythm. GlyR $\alpha 3$ knockout mice also show increased ethanol intake, preference and increased development of conditioned taste aversion to ethanol (Blednov et al., 2015). Lastly, GlyR $\alpha 3$ is involved in hearing, and has important functions in auditory nerve activity (Dlugaiczyk et al., 2016) and signal-in-noise detection (Tziridis et al., 2017).

By comparison, the GlyR $\alpha 4$ subtype is poorly studied, largely because the human gene (GLRA4) is considered to be a pseudogene (Simon et al., 2004) due to the presence of an in-frame stop codon at position 390 (390X) in exon 9, truncating the GlyR subunit within the fourth membrane-spanning domain (M4). This often leads to the incorrect assumption that GLRA4 is not expressed in human brain (Bar-Shira et al., 2015) and is therefore not biologically relevant. However, one mystery that remains unexplained is why the GlyR $\alpha 4$ subunit gene appears to be intact in all other species studied to date (Matzenbach et al., 1994; Harvey et al., 2000) and is even duplicated (GlyR $\alpha 4 \mathrm{a}$ and $\alpha 4 b$ ) in zebrafish (Imboden et al., 2001; Hirata et al., 2010). GlyR $\alpha 4$ subunit expression has been detected by in situ hybridization and PCR assays in chicken embryonic sympathetic neurons, where depolarizing GlyRs have been linked to neurotransmitter release (Boehm et al., 1997; Harvey et al., 2000). GlyR $\alpha 4$ was also found in spinal cord white matter, dorsal root ganglia and the male genital ridge in birds (Harvey et al., 2000). More recently, the development of new subunit-specific antibodies also allowed localization of GlyR $\alpha 4$ in cholinergic amacrine cells in mouse retina (Heinze et al., 2007). Interest in GlyR $\alpha 4$ has recently been rekindled by reports that GLRA4 in humans is potentially involved in intellectual disability, behavioral problems and craniofacial anomalies (Labonne et al., 2016). An 11-year-old female patient (DGDP084) with these symptoms was reported to have a de novo Xq22.2 $110 \mathrm{~kb}$ microdeletion encompassing GLRA4, MORF4L2 and TCEAL. While certain phenotypic features such as cognitive impairment and motor delay overlap with Pelizaeus-Merzbacher disease (PMD) caused by PLP1 mutations at $\mathrm{Xq} 22.2$, this gene was apparently not included in the microdeletion and was not dysregulated by a positional effect (Labonne et al., 2016). Since GlyR $\alpha 4$ transcripts were reduced in the female patient compared to her healthy mother, the authors suggested that loss of one allele of GLRA4 was a plausible explanation for the clinical symptoms observed in this individual. However, in this study, we demonstrate that although the human GlyR $\alpha 4$ subunit gene is expressed and correctly spliced, multiple inactivating substitutions render the human GlyR $\alpha 4$ subunit dysfunctional in modern and ancient humans. We also investigate the physiological properties of inhibitory synaptic currents mediated by $\alpha 4 \beta$ GlyRs in artificial synapses. Finally, we report that the expression pattern and knockdown of the zebrafish GlyR $\alpha 4$ a subunit are consistent with a role for the GlyR $\alpha 4$ subunit in mediating startle and escape responses.

\section{MATERIALS AND METHODS}

\section{Phylogenetic Analysis and Cloning of GlyR $\alpha 4$ Subunit Sequences}

The human GlyR $\alpha 4$ subunit was aligned with orthologs predicted from Denisova, Neanderthal and other vertebrate genomes obtained via Ensembl version 87 (Aken et al., 2017) or the UCSC Genome Browser (Kent et al., 2002). Alignments were made and edited using CLC Main Workbench 6 software. Positions of membrane-spanning domains and other structural features were mapped based on the recent cryo-EM structures of the zebrafish GlyR $\alpha 1$ subunit (3JAE; Du et al., 2015). Human and mouse GlyR $\alpha 4$ subunit cDNAs were amplified from whole-brain first-strand cDNA (Clontech, 
Cat. 637242 and 637301) using primers hGlyR $\alpha 4$-BamHI $5^{\prime}$-caaggatccgccaccatgacaactcttgttcctgc-3'/hGlyR $\quad \alpha 4$-XhoI $5^{\prime}$-ccactcgagtcacagagctggtggatatc- $3^{\prime}$ or mGlyR $\alpha 4$-EcoRI $5^{\prime}$ caagaattcgccaccatgacaactcttgttccagcaa- $3^{\prime} / \mathrm{mGlyR} \quad \alpha 4$-SalI $5^{\prime}$ ccagtcgactcacagtgcctggtggatatctt $-3^{\prime}$, cloned into the expression vector pRK5. Gorilla and Chimp GlyR $\alpha 4$ subunit cDNAs were artificially synthesized from predicted cDNA sequences (Gorilla: XM_004064625.1; Chimp: XM_009439421.2) and recloned into pRK5 using the primers gGlyR $\alpha 4$ EcoRI $5^{\prime}$ caagaattcgecaccatgacaactcttgttcctgaaa- $3^{\prime} /$ gGlyR $\alpha 4$ SalI and $5^{\prime}$-ccagtcgactcacagtgcetggtggatatctt- $3^{\prime}$ and cGlyR $\alpha 4$-EcoRI $5^{\prime}$-caagaattcgccaccatgacaactcttgttcctgcaa-3'/cGlyR $\alpha 4$-SalI $5^{\prime}$ cttgtcgactcacagagcctggtggatatctt- $3^{\prime}$, respectively. In each case, an optimized Kozak sequence was introduced upstream of the start methionine (GCCACC in oligonucleotide sequences).

\section{Site-Directed Mutagenesis and DNA Sequencing}

Sequence changes were introduced into pRK5-human GlyR $\alpha 4$ and pRK5-mouse GlyR $\alpha 4$ using the QuikChange Lightning site-directed mutagenesis kit (Agilent). All expression constructs were confirmed by Sanger DNA sequencing of the entire coding region and analyzed using Sequencher 4.10 (Gene Codes Corporation). Sanger DNA sequencing was performed by DNA Sequencing and Services (MRCPPU, College of Life Sciences, University of Dundee, Scotland).

\section{Primary Culture of Spinal Neurons}

Spinal neurons were prepared using methods as recently described (Dixon et al., 2015). Briefly, E15 timed-pregnant rats were euthanized via $\mathrm{CO}_{2}$ inhalation in accordance with procedures approved by the University of Queensland Animal Ethics Committee. The spinal cords were rapidly removed, triturated and plated onto poly-D-lysine-coated coverslips in a 4 -well plate at a density of $8-10 \times 10^{4}$ cells/well, and cultured for 3-4 weeks until spontaneous inhibitory postsynaptic currents (IPSCs) could be detected. The cells were initially cultured in Dulbecco's Modified Eagles Medium (DMEM) supplemented with $10 \%$ fetal bovine serum (DMEM-FBS). After 24 h the entire DMEM-FBS medium was replaced with Neurobasal medium including 2\% B27 and 1\% GlutaMAX supplements. A second (and final) feed 1 week later replaced half of this medium with fresh Neurobasal medium. Neurons were used in co-culture experiments between 1-4 weeks later.

\section{HEK293 Cell Culture, Transfection and Artificial Synapse Formation}

Artificial synapses were generated as previously described (Zhang Y. et al., 2015). Briefly, HEK293 cells were cultured in DMEM-FBS until $\sim 90 \%$ confluent. One day prior to transfection, they were trypsinized and plated onto glass coverslips in $35 \mathrm{~mm}$ culture dishes at a density of $5 \times 10^{3}$ cells/dish. Homomeric channels were transfected with $0.3 \mu \mathrm{g}$ of $\alpha 4$ subunit constructs (pRK5). Heteromeric channels were transfected at a ratio of 1:50, with $0.02 \mu \mathrm{g}$ GlyR $\alpha 4$ and $1 \mu \mathrm{g} \beta$ subunit constructs (pRK5). $0.1 \mu \mathrm{g}$ EGFP (pEGFP) was used as a transfection marker. For artificial synapses, $0.3 \mu \mathrm{g}$ of mouse neuroligin 2A (pNice) and $0.3 \mu \mathrm{g}$ of rat gephyrin (pCIS) were also added. Transfection was performed via a $\mathrm{Ca}^{2+}$ phosphate-DNA co-precipitation method for 15-20 h in a $3 \% \mathrm{CO}_{2}$ incubator and terminated by washing cells twice with divalent cation-free phosphate buffered saline. Cells were trypsinized the next day, centrifuged and re-suspended in Neurobasal medium (including 2\% B27 and 1\% GlutaMAX supplements) then seeded onto the neurons. One $35 \mathrm{~mm}$ dish of HEK293 cells was typically sufficient to seed four coverslips of neurons. Once seeded with HEK293 cells, the co-cultures were returned to the incubator overnight to allow artificial synapses to form between neurons and transfected HEK293 cells. Cells were used for patch-clamp recording over the following 2-3 days.

\section{Electrophysiology}

Whole-cell patch clamp recordings were performed at room temperature $\left(22 \pm 1{ }^{\circ} \mathrm{C}\right)$. Glycine concentration-response relationships were performed at $-40 \mathrm{mV}$, whereas artificial synapse recordings were performed at $-70 \mathrm{mV}$, both using a Multiclamp 700B amplifier and pClamp10 software (Molecular Devices). Signals were filtered at $4 \mathrm{kHz}$ and sampled at $10 \mathrm{kHz}$. Patch pipettes (4-8 $\mathrm{M} \Omega$ resistance) were fabricated from borosilicate glass (GC150F-7.5, Harvard Apparatus) and filled with an internal solution comprising (in $\mathrm{mM}$ ): $145 \mathrm{CsCl}$, $2 \mathrm{CaCl}_{2}, 2 \mathrm{MgCl}_{2}, 10 \mathrm{HEPES}$ and $10 \mathrm{EGTA}$, adjusted to $\mathrm{pH}$ 7.4 with $\mathrm{CsOH}$. The extracellular solution comprised (in $\mathrm{mM}$ ) $140 \mathrm{NaCl}, 5 \mathrm{KCl}, 2 \mathrm{CaCl}_{2}, 1 \mathrm{MgCl}_{2}, 10$ HEPES and 10 D-glucose, adjusted to $\mathrm{pH} 7.4$ with $\mathrm{NaOH}$.

Outside-out macropatch recordings were performed at $-70 \mathrm{mV}$ using an Axopatch 200B amplifier, pClamp 10 software, filtered at $10 \mathrm{kHz}$ and sampled at $50 \mathrm{kHz}$. Current traces were filtered off-line at $5 \mathrm{kHz}$ for making figures. Pipettes were fire-polished to a resistance of $\sim 10 \mathrm{M} \Omega$ and filled with the same internal solution. Outside-out patches pulled from transfected HEK293 cells were activated by brief $(<1 \mathrm{~ms})$ exposure to glycine using a piezo-electric translator (Siskiyou). The speed of the solution exchange system was regularly calibrated by rapidly switching the solution perfusing an open patch pipette between standard extracellular solution and an extracellular solution that had been diluted by $50 \%$ with distilled water. By monitoring the resulting pipette current, we were able to ensure that the solution perfusing the macropatch was completely exchanged within $200 \mu$ s (Dixon et al., 2014).

\section{Data Analysis}

Analyses of IPSC amplitudes, 10\%-90\% rise times, and decay time constants were performed using Axograph X (Axograph Scientific). Only cells with a stable series resistance of $<25 \mathrm{M} \Omega$ throughout the recording period were selected for analysis. IPSCs were detected using a semi-automated sliding template. Each detected event was visually inspected and only those with no inflections in the rising or decay phases were included. All selected events from a single cell were digitally averaged. Parameters derived from these digitally averaged waveforms were then pooled with those form other cells to obtain group 
data. To calculate macroscopic current decay time constants, digitally averaged macroscopic recordings were fitted with double-exponential functions in Axograph X, and a weighted time constant was calculated from individual time constants ( $\tau 1, \tau 2)$ and their relative amplitude (A1, A2) as follows: $\tau_{\text {weighted }}=(\tau 1 \times \mathrm{A} 1+\tau 2 \times \mathrm{A} 2) /(\mathrm{A} 1+\mathrm{A} 2)$.

Displayed averaged data represent group means \pm SEMs. The Hill equation was used to calculate the saturating current magnitude $\left(I_{\max }\right)$, half-maximal concentration $\left(\mathrm{EC}_{50}\right)$ and Hill coefficient $\left(n_{\mathrm{H}}\right)$ values for glycine activation. Individual concentration-response relationships were fitted using a nonlinear least squares algorithm (SigmaPlot 11.0; Jandel Scientific, San Rafael, CA, USA). Statistical analysis and graphing were performed with SigmaPlot 11.0. Group data were tested for normal probability distribution and for significant differences between groups using one-way ANOVA. Pair-wise comparisons were determined using Dunnett's post hoc test, where $p<0.05$ was taken as the significance threshold.

\section{Fluorescence-Based Imaging}

Cells were imaged using an automated fluorescence-based screening system using EYFP ${ }^{I 152 L}$ fluorescence quench as an indicator of anion influx. In this technique, iodide flowing into the cell binds to and quenches EYFP ${ }^{I 152 L}$ fluorescence, thus providing an indication of the relative activity levels of membrane anion channels (Kruger et al., 2005; Gilbert et al., 2009). Briefly, HEK293 cells were transfected with the plasmid DNAs for wild-type and mutant GlyR $\alpha 4$ constructs together with a pEYFP ${ }^{\mathrm{I152L}}$ expression construct and plated into a 384-well plate. Unless otherwise indicated, all GlyR plasmid DNAs were transfected in equimolar ratios. Within the following 24-32 h, the culture medium in the wells was replaced with extracellular solution ( $140 \mathrm{mM} \mathrm{NaCl}, 5 \mathrm{mM} \mathrm{KCl}, 2 \mathrm{mM} \mathrm{CaCl}$, $1 \mathrm{mM} \mathrm{MgCl}_{2}, 10 \mathrm{mM}$ HEPES, and $10 \mathrm{mM}$ glucose, $\mathrm{pH} 7.4$ using $\mathrm{NaOH}$ ). After $30 \mathrm{~min}$, fluorescence images of each well were obtained twice, before and after the application of $\mathrm{NaI}$ solution (140 mM NaI, $5 \mathrm{mM} \mathrm{KCl,} 2 \mathrm{mM} \mathrm{CaCl}, 1 \mathrm{mM} \mathrm{MgCl}, 10 \mathrm{mM}$ HEPES and $10 \mathrm{mM}$ glucose, $\mathrm{pH} 7.4$ using $\mathrm{NaOH}$ ) containing varying concentrations of glycine. Values were pooled from three to four experiments with three wells each containing $>200$ cells. To determine the glycine dose-response curve, an empirical three or four parameter Hill equation was fitted by a non-linear least squares algorithm using SigmaPlot 11.0 software. Throughout this study, "\% quench" is defined as the (initial fluorescence - final fluorescence) $\times$ 100/initial fluorescence. Thus, a treatment that completely abolished all fluorescence would yield a $100 \%$ quench.

\section{Immunolabeling and Imaging}

Briefly, neuron-HEK293 cell co-cultures were fixed in $4 \%$ paraformaldehyde for $15 \mathrm{~min}$, washed with PBS and then incubated in a blocking solution, containing $1 \%$ bovine serum albumin in PBS, to minimize the background fluorescence caused by non-specific antibody binding. The antibodycontaining solutions were diluted in the same blocking solution. The cultures were first incubated overnight at room temperature with GlyR-specific mouse monoclonal
mAb4a (Synaptic Systems, Germany), diluted 1:6250. After washing with PBS, the cultures were incubated for $3 \mathrm{~h}$ with 1:1000 donkey anti-mouse antibody and labeled with Alexa-555 (ThermoFisher, Australia). After washing thoroughly with PBS, cultures were incubated in a 1:6250 dilution of mouse monoclonal primary antibody against the presynaptic protein, synaptotagmin 1, labeled with Oyster 650 fluorophore (Synaptic Systems, Germany). After overnight incubation, cultures were washed with PBS, and coverslips mounted onto glass slides using DABCO mounting solution prepared as described (Johnson et al., 1982), sealed with acrylic and stored at $4^{\circ} \mathrm{C}$.

\section{Animal Care}

Zebrafish were maintained and used for experiments in accordance with the Norwegian Animal Protection Act and with approval from Mattilsynet (the Norwegian Food Safety Authority). Adults were reared at a maximal density of five animals per liter at $28.5^{\circ} \mathrm{C}$ in a $14 / 10$ (light/dark) cycle environment. Fish were fed a mixture of live artemia and TetraMin fish flakes twice a day. Larvae were raised at $28.5^{\circ} \mathrm{C}$ with a $14 / 10$ day/night light cycle. All experiments were performed at room temperature on 1-3 days post fertilization (dpf) larvae unless stated otherwise.

\section{Zebrafish GlyR $\alpha \mathbf{4 a}$ Gene Trap Line}

The zebrafish SAIGFF16B line was generated by the method described in Kawakami et al. (2010) in which gene trap vectors based on the Tol2 transposable element in combination with the Gal4FF-UAS system were used. The gene trap construct T2KSAIGFF contains the rabbit $\beta$-globin splice acceptor (SA), followed by an internal ribosome entry site (IRES), the coding region for Gal4FF (a modified version of the yeast Gal4 transcription activator) and a downstream polyadenylation site (pA). In zebrafish line SAIGFF16B, this cassette is inserted between exons 1 and 2 of glra4a on zebrafish chromosome $14^{1}$. Gal4FF expression in SAIGFF16B was visualized by creating double transgenic fish carrying a Gal4FF transgene and the GFP reporter gene placed downstream of the Gal4-recognition sequence (UAS:GFP) as previously described.

\section{Zebrafish GlyR $\alpha 4 a$ Knockdown and $\alpha 4 a^{\mathrm{R} 278 \mathrm{Q}}$ Mutant Expression}

Specific antisense translation-blocking and splice-blocking morpholinos (MOs) for GlyR $\alpha 4 a$ morpholinos (MOs) were designed using alignments of exon 1 and exon 7 of zebrafish GlyR genes and synthesized by GeneTools LLC. The morpholino sequences used were: glra4aSMO1 5'-acctagaagagcacaaagagtttca$3^{\prime}$, glra4aSMO2 $5^{\prime}$-acaggaactcattttatgttacctt- $3^{\prime}$, glra4aTBMO $5^{\prime}$-aaatccttatgacctgagggagcat- $3^{\prime}$. We determined the optimal $\mathrm{MO}$ amount required for induction of a specific phenotype post-injection without inducing toxicity and off-target effects. Glra4aTBMO was injected at $2 \mathrm{mM}$, glra4aSMO1

\footnotetext{
${ }^{1}$ http://kawakami.lab.nig.ac.jp/ztrap
} 
and glra4aSMO2 were injected at $1 \mathrm{mM}$. RT-PCR was also used to examine splicing defects caused by glra4aSMO1 and glra4aSMO2 using poly(A) + RNA isolated at 72 hours post fertilization (hpf) using primers glra4aEx6F 5'-GCGGATGACTTGACTCTTCCTCAG-3' and glra4aEx8R 5'-CCTTGAGACGAAGTTGACTGCTGCGTACTC-3' using primers for glral as controls: glra1Ex6F 5'-CTGAC GTTACCTCAGTTTATATTG-3' and glralEx8R 5'-GCG CAGAAGCTCCTTGTGTTGGCG-3'. A dominant-negative mutation p.R278Q in was introduced into a zebrafish GlyR $\alpha 4 \mathrm{a}$ subunit cDNA cloned into the pCS2 expression vector using the QuikChange site directed mutagenesis technique, with primers R278Q1 5'-ccacccagagctccggttcacaagcctcgctac-3' and R278Q2 $5^{\prime}$-gtagcgaggcttgtgaaccggagctctgggtgg- $3^{\prime}$. In vitro transcribed RNA for this construct was made with SP6 RNA polymerase and microinjected into zebrafish embryos at a final concentration of $250 \mathrm{ng} / \mathrm{ml}$.

\section{RESULTS}

\section{GLRA4 Is a Pseudogene in the Human Lineage, but Intact in Other Primates}

To confirm that the human GlyR $\alpha 4$ subunit gene (GLRA4) is transcribed and correctly spliced, we amplified full-length cDNAs from human hippocampal and whole-brain first-strand cDNA (Clontech) using proofreading Pfx DNA polymerase. Sanger DNA sequencing of 10 human GlyR $\alpha 4$ subunit cDNAs and comparison with the GLRA4 consensus sequence (hg38) revealed that: (1) All cDNAs encoded a valine at position 57 (the more common variant of a known SNV; rs4907817, C: 97.005\%; T: 2.995\%); (2) Two cDNA clones had the change c.1345T $>$ C, p.W421R, suggesting that this could be a common polymorphism in human GLRA4. Importantly, all ten cDNA clones contained an in-frame stop codon (TGA) at position 390 in exon 9, truncating the GlyR $\alpha 4$ subunit prematurely within the fourth membrane spanning domain (M4). Despite this interruption, the coding region continues intact, encoding the rest of M4 and a C-terminus with high sequence identity to the corresponding sequence in other species (Figures 1, 2). We found no evidence of RNA editing of this stop codon, nor alternative splicing of GLRA4 transcripts that might restore a full reading frame. We also analyzed the sequence of GLRA4 in a high-coverage genome sequence of a Denisovan, an extinct relative of Neanderthals (Reich et al., 2010). This analysis indicated the sequence of the Denisova GlyR $\alpha 4$ subunit is identical to that of modern day humans, including polymorphic reads at p.W421R, suggesting that GLRA4 has been a pseudogene for at least 30,000-50,000 years.

The human GlyR $\alpha 4$ subunit consensus sequence was aligned with equivalent proteins from primates and other vertebrates, predicted from sequenced genomes accessed via Ensembl release 87. Two alignments are shown in Figures 1, 2-an alignment of human GlyR $\alpha 4$ subunit with orthologs from ancient humans (Denisova) and different ape species, including chimpanzee, gorilla, macaque, baboon and marmoset (Figure 1) and human GlyR $\alpha 4$ subunit aligned with the mouse, rat and zebrafish GlyR $\alpha 4$ subunits (Figure 2). This analysis shows that GlyR $\alpha 4$ subunit sequences are most divergent in the N-terminal signal peptide and the intracellular loop between transmembrane domains M3 and M4. Outside these regions, key differences between the human and Denisovan GlyR $\alpha 4$ subunit and orthologs from ape species include: (1) Extracellular domain: S55, K59, L145, K170, C204 (although note that S55 and C204 are also found in chimpanzee and gorilla sequences); (2) Transmembrane domain M3: I311; and (3) C-terminal extracellular loop: W421. Notably, the stop codon at position 390 is not present in any of the ape, rodent or fish species, where either an arginine or glutamine is found.

\section{Functional Analysis of Recombinant $\alpha 4$ GlyRs in HEK293 Cells}

Initial functional screening was performed using a YFP-based anion influx assay (Figure 3). Extracellular chloride was replaced by iodide because iodide is a much more effective quencher of YFP fluorescence (Kruger et al., 2005). Although the relative permeability of iodide is about 2.3 -fold greater than that of chloride (Fatima-Shad and Barry, 1993), the single channel conductance of GlyRs is not significantly changed when chloride is replaced by iodide (Bormann et al., 1987). As all the mutations investigated in this study are at a considerable distance from the ion selectivity filter (Keramidas et al., 2004) it is reasonable to assume that any difference in relative anion permeability will not have any impact on our results. Unless otherwise indicated, a saturating glycine concentration $(10 \mathrm{mM})$ was used in all experiments. Figure 1 shows sample images of HEK293 cells expressing YFP plus the indicated GlyR constructs, taken before and after the addition of $10 \mathrm{mM}$ glycine. These experiments confirmed that the wild-type human $\alpha 4$ GlyR, when recombinantly expressed in HEK293 cells, does not form functional channels (Figures 3A,B). Restoration of the arginine residue at X390 in two independent constructs (X390R I and II) was insufficient to restore human GlyR $\alpha 4$ subunit function. By contrast, expression of artificially synthesized gorilla and chimp GlyR $\alpha 4$ subunit cDNAs generated robust glycine-gated anion influxes (Figures 3A,B), confirming that the GlyR $\alpha 4$ subunit is functional in two species closely related to humans. Taken together, these data suggest that the human GlyR $\alpha 4$ subunit gene harbors further damaging changes compared to functional mouse, gorilla and chimp GlyR $\alpha 4$ subunits. Outside the variable M3-M4 loops, key differences between the human GlyR $\alpha 4$ subunit and rat/mouse sequences include: (1) Signal peptide: E3D, T8L/T8P; (2) Extracellular domain: S55G, I57V, K59E, S80A, L145P, K170N, V174M, C204Y; (3) Transmembrane domain M3: I311V; and (4) C-terminal extracellular loop: W421R (Figure 2). Again, the X390 stop codon is not present in either mouse or rat GlyR $\alpha 4$ subunits, where an arginine is present.

We assessed the potentially damaging effects of these changes in the GlyR $\alpha 4$ subunit using software packages SIFT and PolyPhen-2. SIFT prediction is based on the degree of 
Human a4

Denisova a4

Chimp a4

Gorilla a4

Macaque a4

Baboon a4

Marmoset $\alpha 4$

Human a4

Denisova a4

Chimp a4

Gorilla a4

Macaque a4

Baboon a4

Marmoset $\alpha 4$

Human a4

Denisova $\alpha 4$

Chimp a4

Gorilla 94

Macaque a4

Baboon a4

Marmoset $\alpha 4$

Human a4

Denisova $\alpha 4$

Chimp a4

Gorilla $\alpha 4$

Macaque a4

Baboon a4

Marmoset $\alpha 4$

Human a4

Denisova a4

Chimp a4

Gorilla $\alpha 4$

Macaque $\alpha 4$

Baboon a4

Marmoset $\alpha 4$

Human a4

Denisova a4

Chimp a4

Gorilla a4

Macaque $\alpha 4$

Baboon a4

Marmoset $\alpha 4$

Human a4

Denisova a4

Chimp a4

Gorilla a4

Macaque a4

Baboon a4

Marmoset $\alpha 4$

Human a4

Denisova a4

Chimp a4

Gorilla a4

Macaque $\alpha 4$

Baboon $a 4$

Marmoset $\alpha 4$

Human a4

Denisova a4

Chimp a4

Gorilla $\alpha 4$

Macaque a4

Baboon a4

Marmoset $\alpha 4$
MTTLVPATLSFLLLWTLPGOVLLRVALA - MTTLVPATLSFLLLWTLPGOVLLRVALA -1 MTTLVPATLSFLLLWTLPGOVLLRVALA -1 MTTLVPETLSFLLLWTLPGQVLLRVALA -1 MTTLVPATLSFLLLWTLPGQVLLRVALA -1 MTTLVPATLSFLLLWTLPGQVLLRVALA -1 MTTL..... SFLLLWTLPGQVLLRVALA -1

KEEVKSGTKGSOPMSPSDFLDKLMGRTSGYDARIRPNFKGPPVNVTCNIFINSFSSVTKT 60 KEEVKSGTKGSOPMSPSDFLDKLMGRTSGYDARIRPNFKGPPVNVTCNIFINSFSSVTKT 60 KEEVKSGTKGSOPMSPSDFLDKLMGRTSGYDARIRPNFKGPPVNVTCNIFINSFSSVTET 60 KEEVKSGTKGSQPMSPSDFLDKLMGRTSGYDARIRPNFKGPPVNVTCNIFINSFSSVTET 60 KEEVKSGTKESOSMSPSDFLDKLMGRTSGYDARIRPNFKGPPVNVTCNIFINSFGSVTET 60 KEEVKSGTKGSOSMSPSDFLDKLMGRTSGYDARIRPNFKGPPVNVTCNIFINSFGSVTET 60 KEEVKSGTKGSOPMSPSDFLDKLMGRTSGYDARIRPNFKGPPVNVTCNIFINSFGSVTET 60 F69 R71 TMDYRVNVFLRQQWNDPRLSYREYPDDSLDLDPSMLDSIWKPDLFFANEKGANFHEVTTD 120 TMDYRVNVFLRQQWNDPRLSYREYPDDSLDLDPSMLDSIWKPDLFFANEKGANFHEVTTD 120 TMDYRVNVFLROOWNDPRLSYREYPDDSLDLDPSMLDSIWKPDLFFANEKGANFHEVTTD 120 TMDYRVNVFLROOWNDPRLSYREYPDDSLDLDPSMLDSIWKPDLFFANEKGANFHEVTTD 120 TMDYRVNVFLRQQWNDPRLSYREYPDDSLDLDPSMLDSIWKPDLFFANEKGANFHEVTTD 120 TMDYRVNVFLRQQWNDPRLSYQEYPDNSLDLDPSMLDSIWKPDLFFANEKGASFHEVTTD 120 $\begin{array}{ccccc}\text { S135 } & \text { L145 } & \text { F165 K170 } & \text { K170 } & \\ \text { NKLLRIFKNGNVLYSIRLTLILSCLMDLKNFPMDIQTCTMOLESFGYTMKDLVFEWLEDA } & 180\end{array}$ NKLLRIFKNGNVLYSIRLTLILSCLMDLKNFPMDIQTCTMQLESFGYTMKDLVFEWLEDA 180 NKLLRIFKNGNVLYSIRLTLILSCPMDLKNFPMDIOTCTMOLESFGYTMNDLVFEWLEDA 180 NKLLRIFKNGNVLYS IRLTLILSCPMDLKNFPMDIOTCTMOLESFGYTMNDLVFEWLEDA 180 NKLLRIFKNGNVLYSIRLTLILSCPMDLKNFPMDIQTCTMQLESFGYTMNDLVFEWLEDA 180 NKLLRIFKNGNVLYSIRLTLILSCPMDLKNFPMDIQTCTMOLESFGYTMNDLVFEWLEDA 180 NKLLRIFKNGNVLYSIRLTLVLSCPMDLKNFPMDIQTCTMOLESFGYTMNDLVFEWLEDA 180 C204 Y209 T211 F214
PAVQVAEGLTLPQF ILRDEKDLGCCTKHYNTGKFTCIEVKFHLEROMGYYLIOMYIPSLL 240 PAVOVAEGLTLPOF ILRDEKDLGCCTKHYNTGKFTCIEVKFHLEROMGYYLIOMYIPSLI 240 PAVOVAEGLTLPOFILRDEKDLGCCTKHYNTGKFTCIEVKFHLEROMGYYLIOMYIPSLL 240 PAVQVAEGLTLPQF ILRDEKDLGCCTKHYNTGKFTCIEVKFHLERQMGYYLIQMYIPSLL 240 PAVQVAEGLTLPQF ILRDEKDLGYCTKYYNTGKFTCIEVKFHLERQMGYYLIQMYIPSLI 240 PAVQVAEGLTLPQF ILRDEKDLGYCTKHYNTGKFTCIEVKFHLERQMGYYLIQMYIPSLL 240 PAVQVAEGLTLPQF ILRDEKDLGYCTKHYNTGKFTCIEVKFHLERQMGYYLIQMYIPSLL 240

IVILSWVSFWINMDAAPARVGLGITTVLTMTTOSSGSRASLPKVSYVKAIDIWMAVCLLF 300 IVILSWVSFWINMDAAPARVGLGITTVLTMTTOSSGSRASLPKVSYVKAIDIWMAVCLLF 300 IVILSWVSFWINMDAAPARVGLGITTVLTMTTQSSGSRASLPKVSYVKAIDIWMAVCLLF 300 IVILSWVSFWINMDAAPARVGLGITTVLTMTTQSSGSRASLPKVSYVKAIDIWMAVCLLF 300 IVILSWVSFWINMDAAPARVGLGITTVLTMTTOSSGSRASLPKVSYVKAIDIWMAVCLLF 300 IVILSWVSFWINMDAAPARVGLGITTVLTMTTOSSGSRASLPKVSYVKAIDIWMAVCLLF 300 IVILSWVSFWINMDAAPARVGLGITTVLTMTTQSSGSRASLPKVSYVKAIDIWMAVCLLF 300

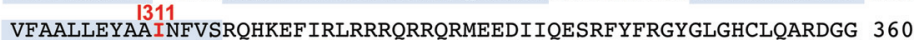
VFAALLEYAAINFVSRQHKEFIRLRRRQRRQRMEEDIIQESRFYFRGYGLGHCLQARDGG 360 VFAALLEYAAVNFVSRQHKEFIRLRRRQRRQRLEEDIIQESRFYFRGYGLGHCLQARDGG 360 VFAALLEYAAVNFVSROHKEFIRLRRRORRORLEEDIIOESRFYFRGYGLGHCLOARDGG 360 VFAALLEYAAVNFVSROHKEFIRLRRRORRORMEEDI IOESRFYFHGYGLGHCLOARDGG 360 VFAALLEYAAVNFVSRQHKEFIRLRRRQRRQRMEEDIIQESRFYFHGYGLGHCLQARDGG 360 VFAALLEYAAVNFVSRQHKEFIRLRRRQRRQRMEEDI IQESRFYFRGYGLGHCLQARDGG 360 PMEGSGIYSPQPPAPLLREGETTRKLYVI90 作 PMEGSGIYSPQPPAPLLREGETTRKLYMDRAKRIDTISRAVFPFTFLIFNIFYWVVYKVL 420 PMEGSGIYSPOPPAPLIREGETMRKLYVDRAKRIDTISRAVFPFTFLIFNIFYWVVYKVL 420 PMEGSGIYSTQPPAPLIREGETMRKLYVDRAKRIDTISRAVFPFTFLIFNIFYWVVYKVL 420 PMEGSGIYSPQPPAPLLREGETMRKLYVDRAKRIDTISRAVFPFTFLIFNIFYWVVYKVL 420

WSEDIHQAL

WSEDIHQAL

RSEDIHOAL

RSEDIHQAL

RSEDIHQAL

RSEDIHQAL

RSEDIHQAL

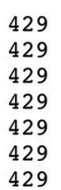

FIGURE 1 | Comparison of glycine receptor (GlyR) $\alpha 4$ subunit sequences in modern and ancient humans and selected primates. The position of the N-terminal signal peptide is indicated by negative numbering, and potential cys-cys loops and membrane-spanning domains (M1-M4) are denoted by gray and blue boxes, respectively. Residues in bold indicate key differences in aligned sequences, while those indicated in red type denote key changes in the human and Denisovan GlyR $\alpha 4$ subunits compared with other primates (although note C204 is also found in gorilla and chimp GlyR $\alpha 4$ ). Residues in purple type indicate key determinants of the GlyR agonist binding site.

conservation of amino acid residues in sequence alignments derived from closely related sequences, collected through PSI-BLAST (Kumar et al., 2009). PolyPhen-2 (Polymorphism Phenotyping v2) is a tool that predicts possible impact of an amino acid substitution on the structure and function of a given protein using straightforward physical and comparative considerations (Adzhubei et al., 2013). We used the mouse GlyR $\alpha 4$ subunit as a starting point, since this subunit is known to be functional in electrophysiological assays (Harvey et al., 2000). The results are summarized in Table 1. While 
Human $\alpha 4$

Mouse $\alpha 4$

Rat $\alpha 4$

$\mathrm{zf} \alpha 4 \mathrm{~A}$

zf $\alpha 4 B$

Human $\alpha 4$

Mouse $\alpha 4$

Rat a4

$\mathrm{Zf} \alpha 4 \mathrm{~A}$

$\mathrm{Zf} \alpha 4 \mathrm{~B}$

Human $\alpha 4$

Mouse $\alpha 4$

Rat $\alpha 4$

Zf $\alpha 4 \mathrm{~A}$

$\mathrm{zf} \alpha \mathrm{ab}$

Human $\alpha 4$ Mouse $\alpha 4$

Rat a4

$\mathrm{zf} \alpha 4 \mathrm{~A}$

zf $\alpha 4 B$

Human $\alpha 4$

Mouse $\alpha 4$

Rat $\alpha 4$

zf $\alpha 4 \mathrm{~A}$

$\mathrm{Zf} \alpha 4 \mathrm{~B}$

Human $\alpha 4$

Mouse a4

Rat $\alpha 4$

$\mathrm{zf} \alpha 4 \mathrm{~A}$

$\mathrm{Zf} \alpha 4 \mathrm{~B}$

Human $\alpha 4$

Mouse $\alpha 4$

Rat $\alpha 4$

$\mathrm{Zf} \alpha 4 \mathrm{~A}$

zf $\alpha 4 B$

Human $\alpha 4$

Mouse a4

Rat $\alpha 4$

$\mathrm{Zf} \alpha 4 \mathrm{~A}$

$\mathrm{zf} \alpha \mathrm{B}$

Human $\alpha 4$

Mouse a4

Rat a4

$\mathrm{zf} \alpha 4 \mathrm{~A}$

Zf $\alpha 4 B$
T-21 S-19

R-5

MTTLVPATLSFLLLWTLPGQVLLRVALA -1 MTTLVPASL-FLLLWTLPGKVLLSVALA -1 MTTLVPASL-FLLLWTLPGKVLLSVALA -1 MLPOVIRIL-YVLSFFFFOGGFIRLGSC -1 MFSVIWRILLELLLVCWMFEGVIRCVFS -1

E3
KEEVKS-GTKGSQPMSPSDFLDKLMGRTSGYDARIRPNFKGPPVNVTCNIFINSFSSVTK
S55 KEDVKS-GLKGSQPMSPSDFLDKLMGRTSGYDARIRPNFKGPPVNVTCNIFINSFGSVTE 59 KEDVKS-GPKGSQPMSPSDFLDKLMGRTSGYDARIRPNFKGPPVNVTCNIFINSFGSVTE 59 KEEIKSSSRPAQKPMSPSDFLDKLMGRTSGYDARIRPNFKGPPVNVTCNIFINSFGSITE 60 KE-LKS-PSVRTKPMSPSDFLDKLMGKTSGYDARIRPNFKGPPVNVTCNIFINSFGSITE 58 F69 R71
TTMDYRVNVFLRQQWNDPRLSYREYPDDSLDLDPSMLDSIWKPDLFFANEKGANFHEVTT 119 TTMDYRVNVFLRQQWNDPRLAYREYPDDSLDLDPSMLDSIWKPDLFFANEKGANFHEVTT 119 TTMDYRVNVFLRQQWNDPRLAYREYPDDSLDLDPSMLDSIWKPDLFFANEKGANFHEVTT 119 TTMDYRLNVFLRQQWNDPRLAYSEYPDASLDLDPSMLDSIWKPDLFFANEKGANFHEVTT 120 TTMDYRLNVFLRQQWNDPRLAYKEYPDDSLDLDPSMLDSIWKPDLFFANEKGANFHEVTT 118 S135 L145

DNKLLRIFKNGNVLYSIRLTLILSCLMDLKNFPMDIQTCTMQLESFGYTMKDLVFEWLED 179 DNKLLRIFKNGNVLYSIRLTLILSCPMDLKNFPMDIQTCTMQLESFGYTMNDLMFEWLED 179 DNKLLRIFKNGNVLYSIRLTLILSCPMDLKNFPMDIQTCTMOLESFGYTMNDLMFEWLED 179 DNKLLRIFQNGNVLYSIRLTLILSCPMDLKNFPMDIQTCTMQLESFGYTMNDLIFEWLSD 180 DNKLLRIFQNGNVLYSIRLTLILSCPMDLKNFPMDTQTCTMQLESFGYTMNDLIFQWLDE 178

C204 Y209 T211 F214
APAVQVAEGLTLPQFILRDEKDLGCCTKHYNTGKFTCIEVKFHLERQMGYYLIQMYIPSL 239 APAVQVAEGLTLPQF ILRDEKDLGYCTKHYNTGKFTCIEVKFHLERQMGYYLIQMYIPSL 239 APAVQVAEGLTLPQF ILRDEKDLGYCTKHYNTGKFTCIEVKFHLERQMGYYLIQMYIPSL 239 NP-VQVADDLTLPQFVLKEEKDLGYCTKHYNTGKFTCIEVKFHLERQMGYYLIQMYIPSL 239 GP-VQVADDLMLPQFVLKEEKDLGYCTKHYNTGKFTCIEVKFHLERQMGYYLIQMYIPSL 237

LIVILSWVSFWINMDAAPARVGLGITTVLTMTTQSSGSRASLPKVSYVKAIDIWMAVCLL 299 LIVILSWVSFWINMDAAPARVGLGITTVLTMTTOSSGSRASLPKVSYVKAIDIWMAVCLL 299 LIVILSWVSFWINMDAAPARVGLGITTVLTMTTQSSGSRASLPKVSYVKAIDIWMAVCLL 299 LIVILSWVSFWINMDAAPARVGLGITTVLTMTTQSSGSRASLPKVSYVKAIDIWMAVCLL 299 LTVILSWVSFWINMDAAPARVGLGITTVLTMTTQSSGSRASLPKVSYVKAIDIWMAVCLL 297

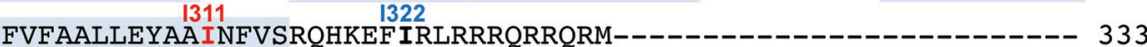

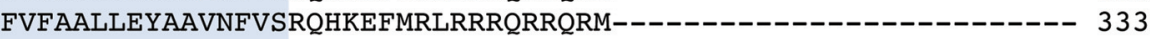

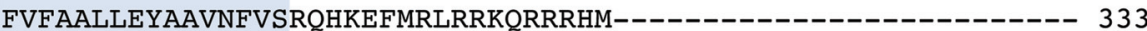
FVFAALLEYAAVNFVSRQHKEF IRLRKKQRRQRI-------------------------- 333 FVFAALLEYAAVNFVSROYKEFFRLRRKLROEQRNRAASGQAGAAETKNKSNNVTGGTPS 357 Q339
G366 A374 R378 ---------EEDIIRESR-FYFRGYGLGHCLOARDGGPMEGSSIYSPOPPTPLLKEG 380 ----------EEDI IREGR-FYFRGYGLGHCLQARDGGPMEGSS IYSPQPPTTLLKEG 380 ----------EEDLVRESRGFYFRGYGLGHCLQTKDGTAVEGSSVFAPPPPVQVLYDG 381 RNAQRQCSACAREEQLASQNQDLYFPGFGIDTSLSG-DGPLSEAAAMFAGLPPGHALF-- 414 T383 X390
ETTRKLYVD*AKRIDTISRAVFPFTFLIFNIFYWVVYKVLWSEDIHQAL ETMRKLYVDRAKRIDTISRAVFPFTFLVFNIFYWVVYKVLRSEDIHQAL ETMRKVYVDRAKRIDTISRAVFPFTFLVFNIFYWVVYKVLRSEDIHQAL EAVRKRFVDRAKRIDTISRAVFPLSFLIFNVFYWITYKVLRHEDIHANP -DIRRRFVEQAKRIDTISRAVFPLSFLVFNVFYWVTYKVLRNEDIHLALRP $\quad 464$

FIGURE 2 | Comparison of GlyR $\alpha 4$ subunit sequences in humans, rodents and zebrafish. The position of the N-terminal signal peptide is indicated by negative numbering, and potential cys-cys loops and membrane-spanning domains (M1-M4) are denoted by gray and blue boxes, respectively. Residues in bold indicate key differences in aligned sequences, while those indicated in blue and red type denote predicted non-damaging (blue) and damaging (red) changes in the human GlyR $\alpha 4$ subunit compared with rodent GlyR $\alpha 4$ subunits predicted by bioinformatics analysis (Table 1). Residues in purple type indicate key determinants of the GlyR agonist binding site.

most substitutions were tolerated/benign, E59K and R421W were predicted to be not tolerated by SIFT, and E59K, P145L, Y204C, V311I and R421W were predicted to be possibly or probably damaging by PolyPhen-2. E59K results in a change from a negatively-charged residue (E, glutamate) to a positivelycharged residue ( $\mathrm{K}$, lysine). $\mathrm{R} 421 \mathrm{~W}$ results in a change from a positively-charged residue ( $\mathrm{R}$, arginine) to a large aromatic residue (W, tryptophan). However, it is noteworthy that most of the amino acids that are predicted to be damaging by SIFT and PolyPhen-2 (K59, L145, I311, W421) are unique to the human GlyR $\alpha 4$ subunit (Figures 1, 2). The exception is C204, which introduces an additional reactive cysteine into the ECD. GlyRs typically have five cysteine residues in the ECD, four of which form disulfide bonds that are important 


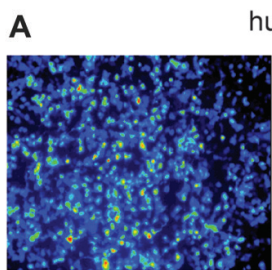

Nal human a4

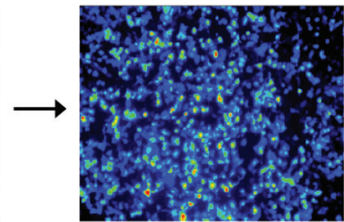

$\mathrm{Nal}+$ glycine

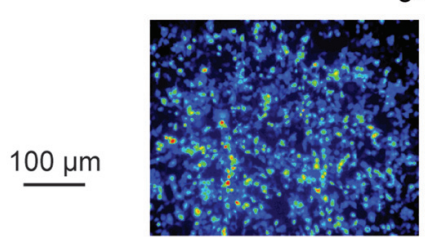

Nal gorilla a4

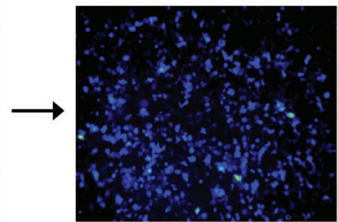

$\mathrm{Nal}+$ glycine

B

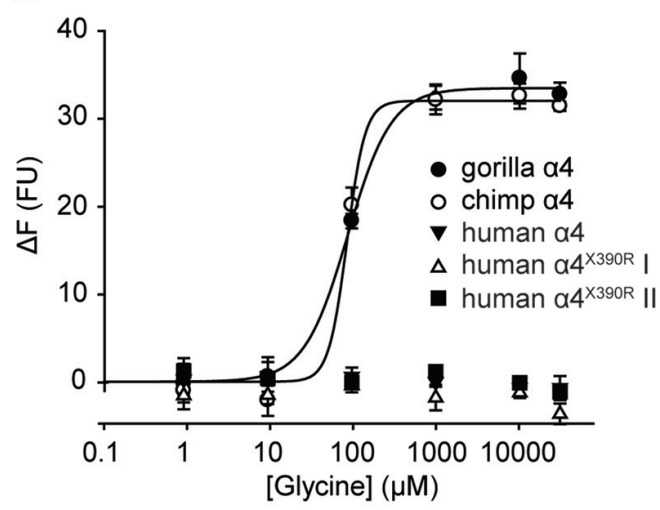

D

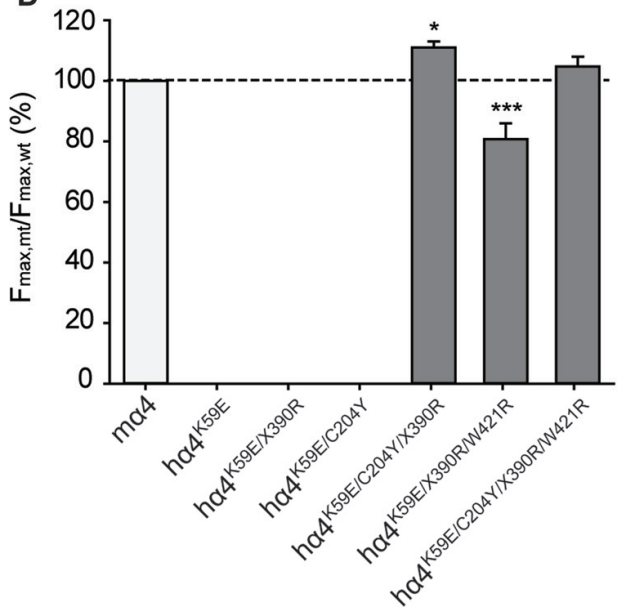

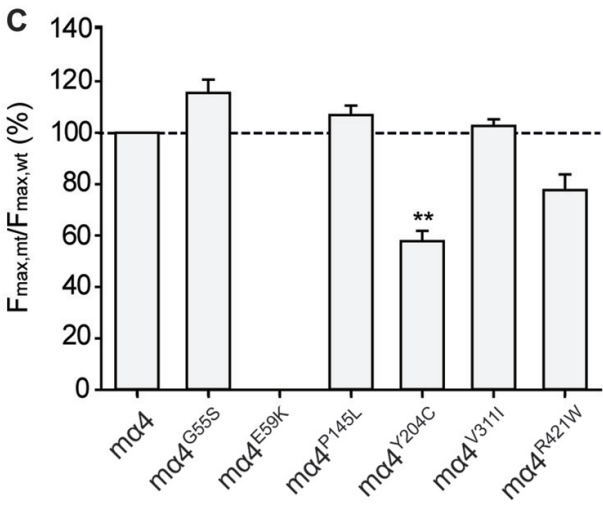

E

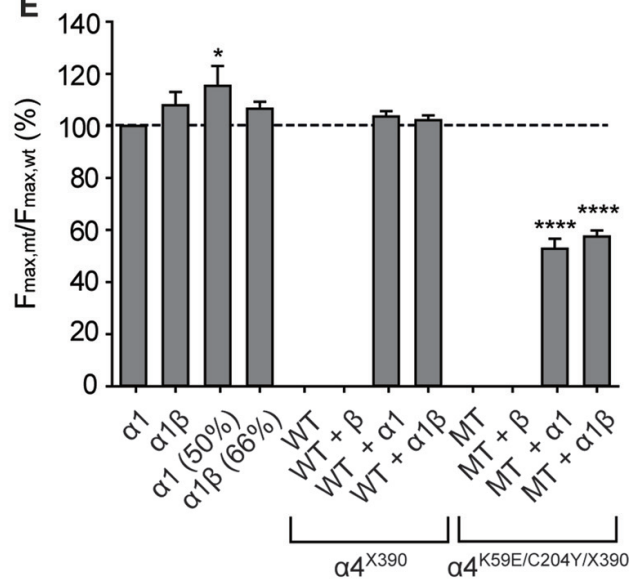

FIGURE 3 | Functional analysis of $\alpha 4$ GlyRs using a fluorescence-based anion influx assay. (A) Sample images from HEK293 cells expressing YFP plus the human $\alpha 4$ GlyR (left panel) or the gorilla $\alpha 4$ GlyR (right panel). Images were recorded in the presence of Nal bathing solution before and after a $10 \mathrm{~s}$ application of $10 \mathrm{mM}$ glycine. (B) Glycine concentration-response results for gorilla, chimpanzee and human GlyR $\alpha 4$ subunits. Two independent full-length human GlyR $\alpha 4$ subunit expression constructs each containing the R390X stop codon were tested. The fluorescence change is plotted against the applied glycine concentration in micromolar. All displayed data points represent the average quench from three experiments with three wells each and $>200$ cells per well. (C) Normalized maximal changes in fluorescence observed upon the addition of Nal containing saturating (10 mM) glycine for the indicated potentially damaging mouse GlyR $\alpha 4$ mutants. The maximal change in fluorescence is presented as the final (quenched) fluorescence value minus the initial fluorescence value. (D) Normalized maximal changes in fluorescence observed upon the addition of Nal containing saturating glycine for the indicated potentially rescued human GlyR $\alpha 4$ subunit receptors. Mouse GlyR $\alpha 4$ subunit represented in light gray, human GlyR $\alpha 4$ subunit mutants in dark gray. (E) Normalized maximal changes in fluorescence observed upon the addition of $\mathrm{Nal}$ containing saturating glycine for wild-type human GlyR $\alpha 4^{\times 390}$ subunits and human GlyR $\alpha 4^{\mathrm{X} 390 / \mathrm{K} 59 \mathrm{E} / \mathrm{C} 204 \mathrm{Y}}$ mutant receptors. GlyR $\alpha 1$ (50\%) means that only half the amount of GlyR $\alpha 1$ was transfected, which represents the amount of GlyR $\alpha 1$ when the GlyR $\alpha 4$ subunit was co-transfected with $\alpha 1$. GlyR $\alpha 1 \beta$ (66\%) represents the corresponding heteromeric state. WT, wild-type GlyR $\alpha 4^{\times 390}$; MT, mutant GlyR $\alpha 4^{\mathrm{K} 59 \mathrm{E} / \mathrm{C} 204 \mathrm{Y} / \mathrm{X} 390}$. In (C-E), mutant values were normalized relative to the wild-type value obtained from the same plate. $p$-values were calculated relative to mouse GlyR $\alpha 4$ and the human GlyR $\alpha 1$ using one-way ANOVA followed by Dunnett's post hoc test: ${ }^{*} p<0.05,{ }^{* *} p<0.01,{ }^{* * *} p<0.001,{ }^{* * * *} p<0.0001$

for cell-surface expression and ECD folding (Vogel et al., 2009). In the GlyR $\alpha 1$ subunit, these form a signature disulfide loop (Cys ${ }^{138}$-Cys ${ }^{152}$ ) that is also found in nAChRs, $5 \mathrm{HT}_{3} \mathrm{Rs}$ and $\mathrm{GABA}_{\mathrm{A}}$ Rs. In addition, a second GlyR-specific disulfide 
TABLE 1 | Prediction of potentially damaging changes in the human Inhibitory glycine receptor (GlyR) $\alpha 4$ subunit compared to the mouse GlyR $\alpha 4$ subunit.

\begin{tabular}{lll}
\hline Change & SIFT & PolyPhen-2 \\
\hline D3E & Tolerated & Benign (score 0) \\
L8T & Tolerated & Benign (score 0.002) \\
G55S & Tolerated & Benign (score 0.003) \\
E59K & Not tolerated (change in charge) & Probably damaging (0.972) \\
A80S & Tolerated & Benign (score 0.046) \\
P145L & Tolerated & Possibly damaging (0.951) \\
N170K & Tolerated & Benign (score of 0.044) \\
M173V & Tolerated & Benign (score of 0) \\
Y204C & Tolerated & Probably damaging (0.993) \\
V311I & Tolerated & Possibly damaging (0.924) \\
M322I & Tolerated & Benign (score of 0) \\
R339Q & Tolerated & Benign (score of 0.01) \\
S366G & Tolerated & Benign (score of 0) \\
T374A & Tolerated & Benign (score of 0) \\
K378R & Tolerated & Benign (score of 0) \\
M383T & Tolerated & Benign (score of 0) \\
R390X & - & - \\
V408I & Tolerated & Benign (score of 0) \\
R421W & Not tolerated (charge-bulky residue) & Probably damaging (1) \\
\hline Individual & amino acid substitutions were made in the mouse GlyR \\
a4 subunit & (Figure 2; Harvey et al., 2000) & and potentially damaging \\
effects & were assessed using SIFT (http://sift.jcvi.org/) and PolyPhen-2 \\
(htttp://genetics.bwh.harvard.edu/pph2/). & \\
&
\end{tabular}

bond is formed (Cys $\left.{ }^{198}-\mathrm{Cys}^{209}\right)$, leaving one cysteine $\left(\mathrm{Cys}^{41}\right)$ unpaired (Vogel et al., 2009). The equivalent residues in the human GlyR $\alpha 4$ subunit are $\mathrm{Cys}^{144}-\mathrm{Cys}^{158}, \mathrm{Cys}^{205}-\mathrm{Cys}^{216}$ and $\mathrm{Cys}^{47}$. However, the human, chimp and gorilla GlyR a4 subunits all contain an extra cysteine $\left(\mathrm{Cys}^{204}\right)$ that may have a significant impact on disulfide bond formation (Figure 1).

To test the impact of the potentially damaging residues in the human GlyR a4, we introduced G55S, E59K, P145L, Y204C, V311I and R421W changes into the functional mouse GlyR a4 subunit (Harvey et al., 2000). Upon functional expression in HEK293 cells, we found that the E59K substitution completely precluded functional expression, whereas the Y204C change significantly reduced the maximal change in fluorescence, suggesting either impaired receptor trafficking, and/or receptor function (Figure 3C). The other mutations had no deleterious effect (Figure 3C). To test whether human GlyR $\alpha 4$ function could be restored by reversing these mutations, residues in human GlyR $\alpha 4$ were changed to the equivalent residues present in mouse GlyR a4. Since E59K precluded functional expression in mouse GlyR $\alpha 4$, we made the K89E change alone and together with other potentially damaging mutations, K59E, K59E/C204Y, $\mathrm{K} 59 \mathrm{E} / \mathrm{W} 421 \mathrm{R}$ and $\mathrm{K} 59 \mathrm{E} / \mathrm{C} 204 \mathrm{Y} / \mathrm{W} 421 \mathrm{R}$, in both the truncated (X390) and restored (R390) human GlyR $\alpha 4$ subunit. As shown in Figure 3D, GlyR function could not be restored by introducing $\mathrm{K} 59 \mathrm{E}$ alone in either the GlyR $\alpha 4^{\mathrm{X} 390}$ or $\alpha 4^{\mathrm{R} 390}$ backgrounds. However, introduction of $\mathrm{K} 59 \mathrm{E}$ with either C204Y or W421R restored function in the GlyR $\alpha 4^{\mathrm{R} 390}$ background. This strongly suggests that multiple damaging changes-in particular K59E and X390R, but also C204Y and W421R-completely preclude function of the human GlyR a4 subunit in vivo.
Since GlyRs truncated in the M3-M4 loop can be incorporated into functional GlyRs when co-expressed with wild-type GlyR subunits (e.g., the hyperekplexia mutation p.E375X, Bode et al., 2013), we tested whether wild-type human GlyR a4 subunits could act as negative regulators of other GlyR subtypes, as proposed by Labonne et al. (2016). While wild-type homomeric GlyR $\alpha 1$ and heteromeric $\alpha 1 \beta$ subunit GlyRs generated robust glycine-induced fluorescence responses (Figure 3E), the wild-type human GlyR $\alpha 4$ subunit harboring the X390 truncating mutation (GlyR $\alpha 4^{\mathrm{X} 390}$ ) was incapable of forming functional homomeric or heteromeric GlyRs (Figures 3B,E). Co-expression of human GlyR $\alpha 1$ and $\alpha 4^{\mathrm{X} 390}$, or $\alpha 1, \alpha 4^{\mathrm{X} 390}$ and $\beta$ subunits did not result in significant changes in maximal fluorescence quench, suggesting that co-expression of the native human GlyR $\alpha 4^{\mathrm{X} 390}$ does not influence function of homomeric $\alpha 1$ or heteromeric $\alpha 1 \beta$ GlyRs (Figure 3E). An artificial mutant GlyR $\alpha 4^{\mathrm{X} 390}$ subunit that also incorporated the $\mathrm{K} 59 \mathrm{E}$ and $\mathrm{C} 204 \mathrm{Y}$ mutations was also incapable of forming functional homomeric or heteromeric GlyRs, but did reduce the observed maximal fluorescence quench for when co-expressed with GlyR $\alpha 1$ or $\alpha 1 \beta$ GlyRs (Figure 3E), suggesting that the artificial mutant GlyR $\alpha 4^{\mathrm{K} 59 \mathrm{E} / \mathrm{C} 204 \mathrm{Y} / \mathrm{X} 390}$ was incorporated into functional pentamers.

We next sought to confirm the key results from Figure 3 via whole-cell electrophysiology in HEK293 cells. Examples of current traces recorded in response to increasing glycine concentrations for a subset of the investigated constructs are shown in Figure 4A, with averaged concentration-response relationships for all investigated constructs presented in Figures 4B,C. First, glycine concentration-response relations were determined for human $\alpha 1$ and mouse $\alpha 4$ GlyRs (Figure 4B, Table 2). Their respective $\mathrm{EC}_{50}$ values were not significantly different from each other. We next characterized the human GlyR $\alpha 4^{\mathrm{K} 59 \mathrm{E} / \mathrm{C} 204 \mathrm{Y} / \mathrm{X} 390 \mathrm{R}}, \alpha 4^{\mathrm{K} 59 \mathrm{E} / \mathrm{X} 390 \mathrm{R} / \mathrm{W} 421 \mathrm{R}}$ and $\alpha 4^{\mathrm{K} 59 \mathrm{E} / \mathrm{C} 204 \mathrm{Y} / \mathrm{X} 390}$ mutants. The glycine $\mathrm{EC}_{50}$ values for the human $\alpha 4^{\mathrm{K} 59 \mathrm{E} / \mathrm{C} 204 \mathrm{Y} / \mathrm{X} 390 \mathrm{R}}$ and $\alpha 4^{\mathrm{K} 59 \mathrm{E} / \mathrm{X} 390 \mathrm{R} / \mathrm{W} 421 \mathrm{R}}$ GlyRs were significantly reduced relative to those recorded for the human $\alpha 1$ and mouse $\alpha 4$ GlyRs (Figures 4A,B, Table 2). Although the truncated mutant $\alpha 4^{\mathrm{K} 59 \mathrm{E} / \mathrm{C} 204 \mathrm{Y} / \mathrm{X} 390}$ GlyR was non-functional when expressed alone, co-expression with the wild-type human GlyR $\alpha 1$ subunit resulted in a significant increase in glycine $\mathrm{EC}_{50}$ (from $64 \pm 8$ to $350 \pm 29 \mu \mathrm{M}$, $p<0.001$; Figures 4A,B, Table 2) suggesting that the truncated $\alpha 4^{\mathrm{K} 59 \mathrm{E} / \mathrm{C} 204 \mathrm{Y} / \mathrm{X} 390}$ mutant can co-assemble with human GlyR $\alpha 1$. However, restoration of two non-conserved residues, E59K and Y204C, was required for co-assembly and it is important to note that this artificial mutant does not exist in vivo. Taken together, these data indicate that the wild-type human $\alpha 4^{\mathrm{X} 390}$ GlyR does not contribute to functional GlyRs and cannot act as a negative regulator of other GlyR subtypes.

Figure 3A also suggests that the gorilla and chimp $\alpha 4$ GlyRs express strongly, despite incorporating $\mathrm{Cys}^{204}$ residues that contribute to the impairment of the functional expression of human $\alpha 4$ GlyRs. To confirm this, we quantified the glycine concentration-response relationships of the mouse 
A

human $\alpha 4^{\mathrm{K} 59 \mathrm{E} / \mathrm{C} 204 \mathrm{Y} / \mathrm{X} 390 \mathrm{R}}$

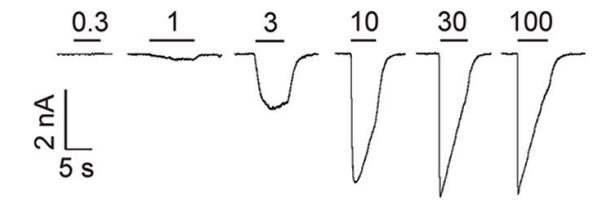

human $\alpha 4^{\mathrm{K} 59 \mathrm{E} / \mathrm{C} 204 \mathrm{Y}}+\alpha 1$

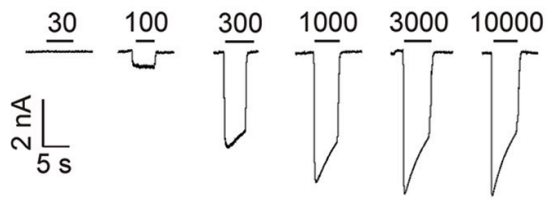

mouse a4

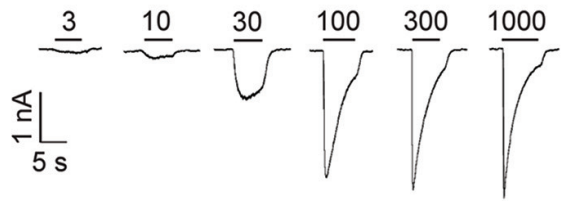

gorilla $a 4$

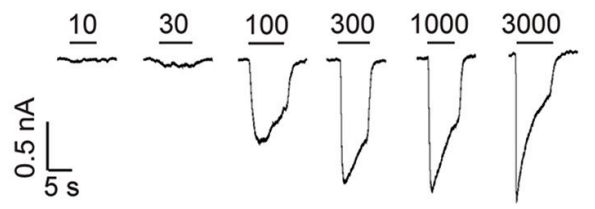

B

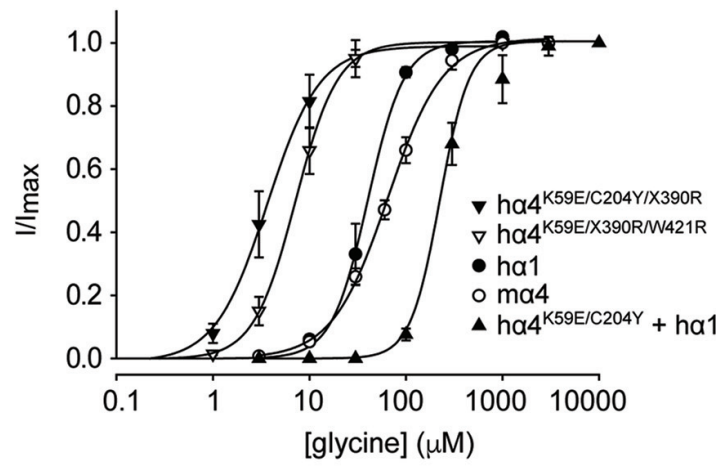

C

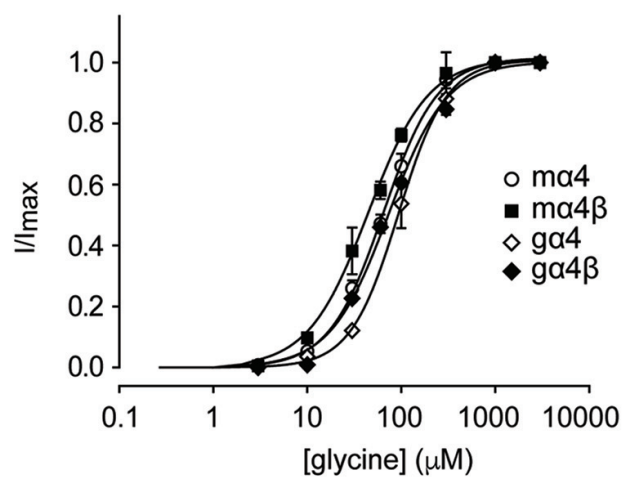

FIGURE 4 | Functional analysis of human, mouse and gorilla $\alpha 4$ subunit GlyRs using whole-cell patch-clamp electrophysiology. (A) Glycine dose-response sample traces for truncated and full-length human $\alpha 4^{\mathrm{K} 59 \mathrm{E} / \mathrm{C} 204 \mathrm{Y}} \mathrm{GlyRs}$. The truncated form was co-expressed with the wild-type GlyR $\alpha 1$ subunit. Glycine dose-response sample traces for wild-type mouse and gorilla $\alpha 4$ GlyRs are also shown. Filled bars indicate the applied glycine concentration in micromolar. (B) Normalized, averaged glycine dose-response results for the indicated human GlyRs, together with wild-type mouse a4 subunit GlyRs for comparison. Parameters of best fit to the Hill equation are summarized in Table 2. (C) Normalized, averaged glycine dose-response results for the indicated mouse and gorilla $\alpha 4$ subunit GlyRs. Parameters of best fit to the Hill equation are summarized in Table 2.

$\alpha 4$ and $\alpha 4 \beta$ GlyRs and the gorilla $\alpha 4$ and $\alpha 4 \beta$ GlyRs. When expressing heteromeric GlyRs, we transfected $\alpha 4$ and $\beta$ subunits at a ratio of $1: 100$ given that has been shown to maximize the expression of heteromeric GlyRs in HEK293 cells (Zhang Y. et al., 2015). Examples of currents recorded in response to increasing glycine concentration for the mouse and gorilla homomeric GlyRs are shown in Figure $\mathbf{4 A}$, with averaged results for homomeric and heteromeric GlyRs presented in Figure 4C and Table 2. There was no significant difference in $\mathrm{EC}_{50}$ values among the four receptors,

TABLE 2 | Properties of GlyRs measured using whole-cell patch-clamp electrophysiology.

\begin{tabular}{|c|c|c|c|}
\hline GlyR construct & $\mathrm{EC}_{50}(\mu \mathrm{M})$ & $n_{\mathrm{H}}$ & $I_{\max }(\mathrm{nA})$ \\
\hline Human $\alpha 1$ & $41 \pm 6$ & $2.7 \pm 0.3$ & $2.9 \pm 0.3$ \\
\hline Human $\alpha 4^{\mathrm{K} 59 \mathrm{E} / \mathrm{X} 390 \mathrm{R} / \mathrm{W} 421 \mathrm{R}}$ & $7.6 \pm 1.3^{*}$ & $2.2 \pm 0.1$ & $2.3 \pm 0.5$ \\
\hline Human $\alpha 4^{\mathrm{K} 59 \mathrm{E} / \mathrm{C} 204 \mathrm{Y} / \mathrm{X390R}}$ & $4.3 \pm 1.3^{*}$ & $2.1 \pm 0.3$ & $2.8 \pm 0.5$ \\
\hline Mouse $\alpha 4$ & $61 \pm 10$ & $1.6 \pm 0.1$ & $2.8 \pm 0.6$ \\
\hline Mouse $\alpha 4 \beta$ & $45 \pm 13$ & $1.8 \pm 0.1$ & $3.8 \pm 0.5$ \\
\hline Gorilla $\alpha 4$ & $86 \pm 16$ & $1.8 \pm 0.1$ & $1.7 \pm 0.7$ \\
\hline
\end{tabular}

$E C_{50}$ values, Hill coefficients $\left(n_{H}\right)$ and the maximal currents $\left(I_{\max }\right)$ are represented. $p$-values were calculated relative to a1 subunit GlyRs using one-way ANOVA followed by Dunnett's post hoc test: ${ }^{*} p<0.05,{ }^{* * *} p<0.0001$. 
indicating no deleterious effect of the gorilla $\alpha 4$ GlyR Cys ${ }^{204}$ residue.

\section{Properties of IPSCs Mediated by Mouse and Gorilla $\alpha 4 \beta$ GlyRs in Artificial Synapses} Whole-cell recordings from transfected HEK293 cells in co-culture with spinal neurons regularly exhibited robust, spontaneous IPSCs mediated by mouse $\alpha 4$ and $\alpha 4 \beta$ GlyRs and gorilla $\alpha 4$ and $\alpha 4 \beta$ GlyRs (Figure 5A). Figure 5B shows digitally averaged and normalized IPSCs from single HEK293 cells expressing mouse and gorilla $\alpha 4 \beta$ GlyRs, together with a control IPSC mediated by $\alpha 1 \beta$ GlyRs. Mean IPSC $10 \%-90 \%$ rise times, decay time constants and amplitudes, presented in Figures 5C-E, reveal no significant differences among the four $\alpha 4$-subunit containing GlyRs. However, it is evident from Figure 5B that IPSCs mediated by $\alpha 4 \beta$ GlyRs exhibit dramatically slower decays than those mediated by $\alpha 1 \beta$ GlyRs. Indeed, the mean decay time constant of IPSCs mediated by $\alpha 4$-containing GlyRs ( $\sim 80 \mathrm{~ms}$; Figure 5C) is drastically slower than those mediated by either $\alpha 1 \beta, \alpha 2 \beta$ or $\alpha 3 \beta$ GlyRs (7.2, 25.7 and $9.7 \mathrm{~ms}$, respectively; Zhang Y. et al., 2015).

To investigate the mechanism responsible for the slow IPSC decay, we first sought to determine whether $\alpha 4 \beta$ GlyRs were located in clusters apposed to presynaptic terminals in artificial synapses. We employed immunofluorescence to compare the degree to which mouse $\alpha 4$ and $\alpha 4 \beta$ GlyRs co-localized with synaptotagmin, a presynaptic marker. Sample images of single co-cultured HEK293 cells transfected with $\alpha 4$ and $\alpha 4 \beta$ GlyRs, respectively, are shown in Figure 5F. The percentage overlap between synaptotagmin and GlyR immunofluorescence was $36 \pm 13 \%$ ( $n=4$ cells) for $\alpha 4$ GlyRs and $69 \pm 5 \%$ ( $n=7$ cells $)$ for $\alpha 4 \beta$ GlyRs. The difference was significant ( $p<0.02$ by ANOVA), indicating that $\alpha 4 \beta$ GlyRs exhibit more pronounced clustering. This is expected given that $\beta$ subunits mediate GlyR anchoring to the synapse via a direct interaction with gephyrin (Meyer et al., 1995), which are both recombinantly expressed in our artificial synapse system.

To determine whether the IPSC decay rate was determined by the intrinsic receptor closing rate, we recorded ensemble currents from outside-out patches excised from HEK293 cells that expressed either mouse $\alpha 4$ or $\alpha 4 \beta$ GlyRs. To mimic synaptic activation conditions, we applied a saturating $(3 \mathrm{mM})$ glycine concentration for $1 \mathrm{~ms}$ via a piezoelectric translation device. Examples of ensemble currents activated under these conditions for the two isoforms are shown in Figure 6A with the mean deactivation time constants and 10\%-90\% rise times (averaged from 6 patches each) summarized in Figures 6B,C. A two-way ANOVA revealed no statistically significant difference in rise times. However, the mean decay time constant for $\alpha 4$ GlyRs (661 $\pm 103 \mathrm{~ms}$ ) was significantly slower than that for $\alpha 4 \beta$ GlyRs (354 $\pm 48 \mathrm{~ms} ; p<0.05$ by ANOVA). These decay times are substantially slower than those for $\alpha 1$ and $\alpha 1 \beta$ GlyRs recorded under similar conditions. Homomeric $\alpha 1$ subunit GlyRs decay with a time constant of $24 \mathrm{~ms}$ (Scott et al., 2015), whereas heteromeric $\alpha 1 \beta$ subunit GlyRs decay with time constants that range from $16 \mathrm{~ms}$ (Scott et al., 2015)

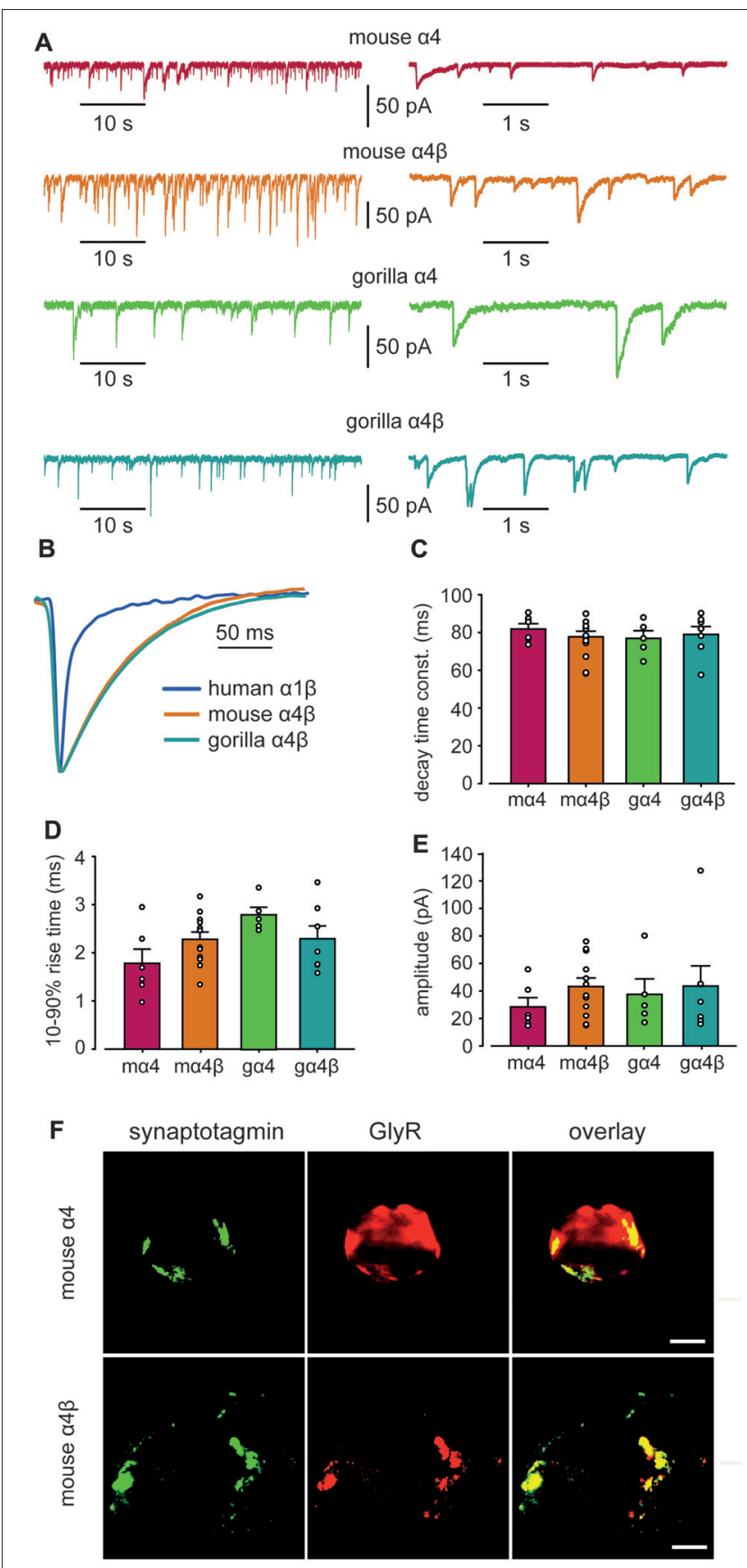

FIGURE 5 | Properties of spontaneous inhibitory postsynaptic currents (IPSCs) recorded from artificial synapses incorporating mouse $\alpha 4$, mouse $\alpha 4 \beta$, gorilla $\alpha 4$ and gorilla $\alpha 4 \beta$ GlyRs. (A) Representative recordings of IPSCs from HEK293 cells expressing each isoform at two temporal scales. (B) Averaged (from 20 to 100 events), normalized IPSCs from individual cells expressing mouse $\alpha 4$ and $\alpha 4 \beta$ GlyRs. A corresponding waveform from a human $\alpha 1 \beta$ GlyR is also shown. (C-E) Mean IPSC decay time constants, 10\%-90\% rise times and amplitudes. $n$ values ranged from 5 to 12. Means were tested for significance using one-way ANOVA although no statistically significant differences were found. (F) Images of HEK293 cells that receive artificial synaptic contacts from co-cultured spinal neurons. Images in the top and bottom rows are from the same cells that were transfected with mouse $\alpha 4$ and $\alpha 4 \beta$ GlyRs, respectively. Immunolabeling for synaptotagmin (green), GlyR (red) and overlay (yellow) are shown for each cell. Scale bars $=5 \mu \mathrm{m}$. 
A mouse $\alpha 4 \beta$

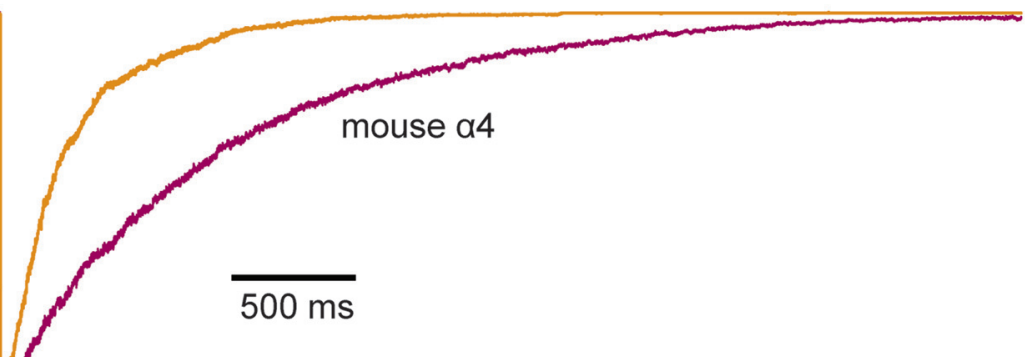

B

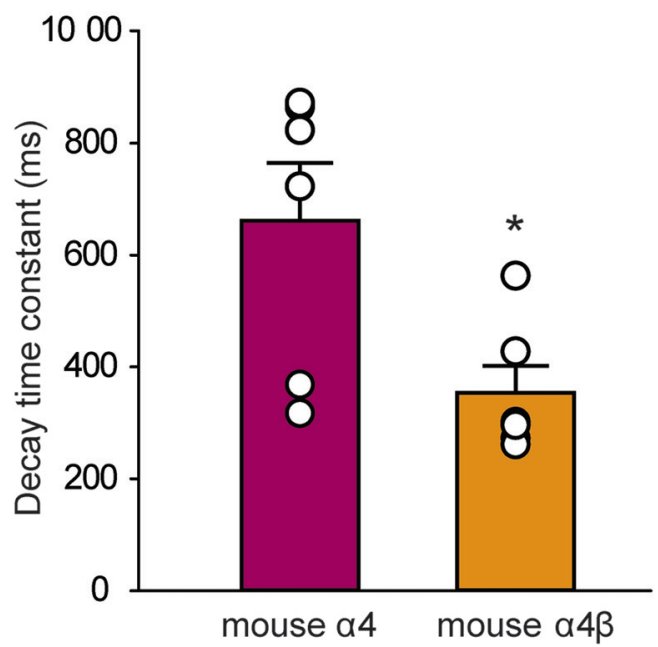

c

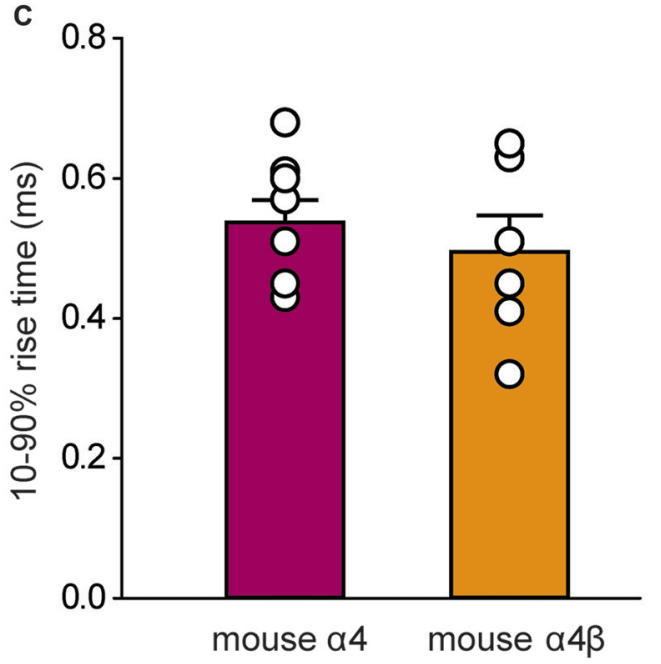

FIGURE 6 | Outside-out macropatch recordings of currents mediated by mouse $\alpha 4$ and $\alpha 4 \beta$ GlyRs. (A) Sample recordings from macropatches expressing the indicated isoforms in response to $\leq 1 \mathrm{~ms}$ applications of saturating ( $3 \mathrm{mM})$ glycine. Patches were clamped at $-70 \mathrm{mV}$ and $15-40 \mathrm{sweeps}$ were averaged from each recorded patch. (B) Mean deactivation time constants reveal a significant difference between the two isoforms $\left({ }^{*} p=0.02, n=6\right.$ patches for both). (C) Mean $10 \%-90 \%$ activation times reveal no significant difference between isoforms.

to $26 \mathrm{~ms}$ (Zhang et al., 2016). Thus, the deactivation time constant for the $\alpha 4 \beta$ GlyR is an order of magnitude slower than for the $\alpha 1 \beta$ GlyR. Moreover, we observed that, as for $\alpha 1$ subunit GlyRs, currents mediated by $\alpha 4$-containing GlyRs exhibit faster decay times when expressed at synapses. For instance, $\alpha 1 \beta$ and $\alpha 4 \beta$ GlyR currents decay $\sim 3-4$-fold faster at synapses compared to macropatch recordings, likely reflecting the presence of intracellular modulatory factors that shape IPSCs that are removed upon macropatch excision.

\section{A Zebrafish Gene Trap Line Reveals glra4a Expression in Brainstem and Spinal Cord Neurones}

In order to learn more about the biological role of GlyR $\alpha 4$ we turned to zebrafish, which have two GlyR $\alpha 4$ subunit genes (glra4a and glra4b) with distinct expression patterns (Imboden et al., 2001; Hirata et al., 2010; Hensley et al., 2011). In 24 hpf embryos, glra4b (previously known as aZ4) expression was previously reported to be restricted to the rhombencephalic portion of the midbrain-hindbrain boundary and the rhombic lip, but from $52 \mathrm{hpf}$ was confined to the retina (Imboden et al., 2001; Hensley et al., 2011). By contrast, glra4a (previously known as aZ2) was reported to be more widely expressed in the olfactory pits, the mesencephalon, the rhombencephalon and the somites (Imboden et al., 2001). In this study, we used a novel Tol2 based gene-trap line (Kawakami et al., 2010), to map the expression of glra4a in more detail. The zebrafish line SAIGFF16B contains a reporter cassette integrated into glra $4 a$ between exon 1 and exon 2 . This cassette encodes the yeast transcription factor activator protein GAL4, flanked by IRES and a polyadenylation signal (Figure 7A). GAL4 works efficiently as a transcription factor when it binds to an upstream activator sequence (UAS) located near a fluorescent protein such as enhanced green fluorescent protein (EGFP). The zebrafish glra4a:GAL4 gene-trap line was therefore crossed with a UAS:EGFP line. The offspring express GAL4, which binds to the UAS and subsequently triggers the 

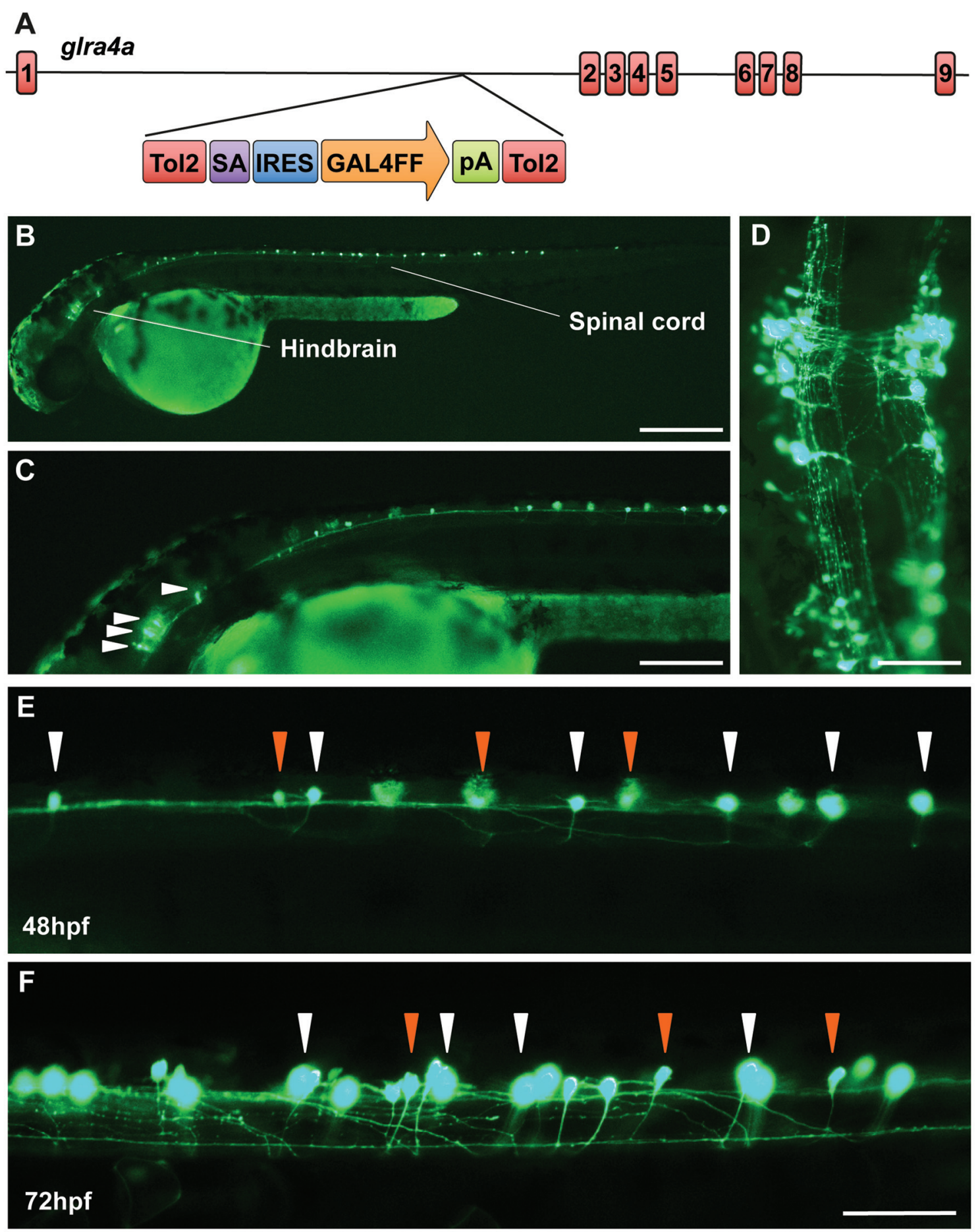

FIGURE 7| A novel zebrafish glra4a gene trap reveals expression in the zebrafish brain and spinal cord. (A) The zebrafish SAIGFF16B line contains the gene trap construct T2KSAGFF inserted between exons 1 and 2 of glra4a. This cassette contains a splice acceptor (SA), followed by an internal ribosome entry site (IRES), the coding region for the Gal4FF transcription activator and a polyadenylation site (pA). Gal4FF expression in SAIGFF16B was visualized by creating double transgenic fish carrying the Gal4FF transgene and a GFP reporter gene placed downstream of the Gal4-recognition sequence (UAS:GFP). (B,C) GFP expression in the glra4a gene-trap line at 48 hours post fertilization (hpf) reveals that glra $4 a$ is predominantly expressed four clusters of hindbrain commissural neurons and selected spinal commissural interneurons. (D) High magnification dorsal view of neurons indicated by arrows in (C). (E,F) Images show a portion of the zebrafish spinal cord at $48 \mathrm{hpf}$ (E) and $72 \mathrm{hpf}$ (F) showing glra4a expression in commissural primary (CoPA, white arrows) and secondary (CoSA, orange arrows). Scale bars: (B): $500 \mu \mathrm{m}$; (C); $250 \mu \mathrm{m}$; (D): $150 \mu \mathrm{m}$; (E,F): $50 \mu \mathrm{m}$. 
A

Control

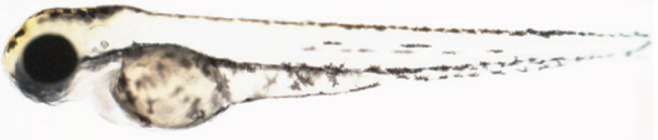

a4aTMO

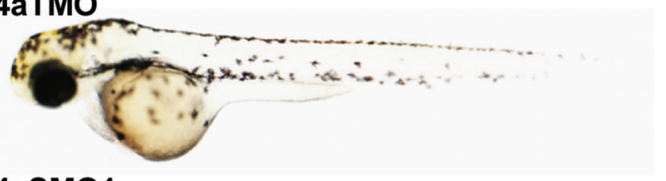

a4aSMO1

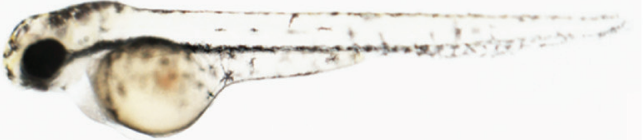

a4aSMO2

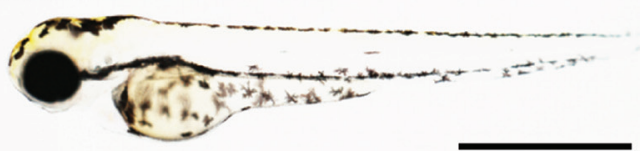

SMO1

$\mathrm{SMO} 2$

WT

$\mathrm{SMO} 2$

WT

SMO1

$\mathrm{SMO} 2$

WT

SMO1

$\mathrm{SMO} 2$

WT

SMO1

$\mathrm{SMO} 2$

WT

D

SMO1 ....YCTKHYNTGVLREGH *

SMO2 M1

WT

SMO2

.... YCTKH

WT

B Ex6F
Ex6R
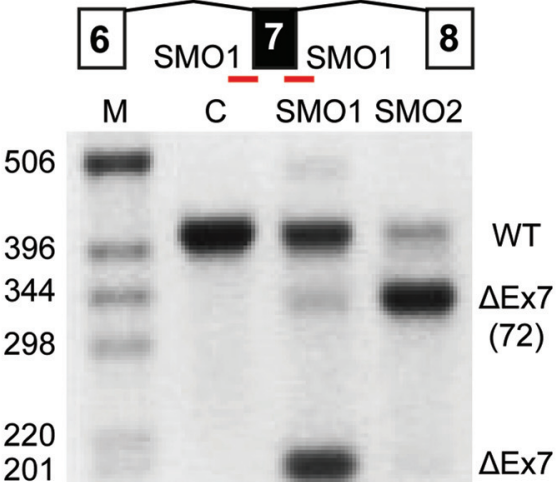

$\alpha 4 a(215)$

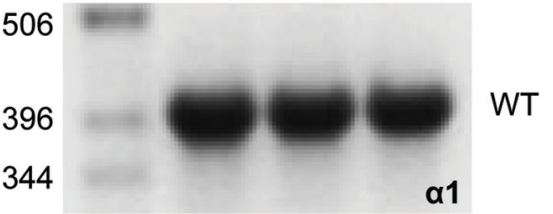
$\begin{array}{llllllllllllllllllll}\text { Y } & C & T & K & H & Y & N & T & G & K & F & T & C & I & E & V & K & F & H & L\end{array}$ TACTGCACTAAGCACTACAACACAGGTAAATTCACCTGCATTGAGGTGAAGTTTCACTTA TACTGCACTAAGCACTACAACACAGGTAAATTCACCTGCATTGAGGTGAAGTTTCACTTA $\begin{array}{llllllllllllllllllllll}E & R & Q & M & G & Y & Y & L & I & Q & M & Y & I & P & S & L^{M 1} & L & I & V & I\end{array}$ GAGAGACAGATGGGCTACTATCTCATTCAGATGTACATCCCCAGCCTGCTGATTGTCATC GAGAGACAGATGGGCTACTATCTCATTCAGATGTACATCCCCAGCCTGCTGATTGTCATC

$$
\begin{array}{llllllllllllllllllllll}
\text { L } & S & \text { W } & \text { W } & \text { V } & \text { S } & \text { F } & \text { W } & \text { I } & \text { N } & \text { M } & \text { D } & \text { A } & \text { A } & \text { P } & \text { A } & \text { R } & \text { V } & \text { G } & \text { I } & \text { G }
\end{array}
$$

TTGTCTTGGGTGTCTTTCTGGATCAATATGGATGCGGCACCGGCTCGGTTGTCTTGGGTGTCTTTCTGGATCAATATGGATGCGGCACCGGCTCGGGTGGGTTTGGGT

$$
\begin{array}{lllllllllllllllllllll} 
& \mathrm{I} & \mathrm{T} & \mathrm{T} & \mathrm{V} & \mathrm{L} & \mathrm{T} & \mathrm{M} & \mathrm{T} & \mathrm{T} & \mathrm{Q} & \mathrm{S} & \mathrm{S} & \mathrm{G} & \mathrm{S} & \mathrm{R} & \mathrm{A} & \mathrm{S} & \mathrm{L} & \mathrm{P} & \mathrm{K}
\end{array}
$$

ATCACCACCGTGCTGACCATGACCACCCAGAGCTCCGGTTCAAGAGCCTCGCTACCCAAG

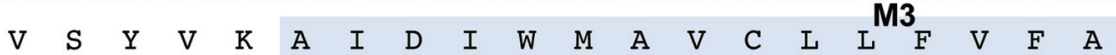
GTGTCCTACGTGAAGGCCATTGACATCTGGATGGCTGTTTGTCTGCTGTTCGTGTTTGCT GTGTCCTACGTGAAGGCCATTGACATCTGGATGGCTGTTTGTCTGCTGTTCGTGTTTGCT GTGTCCTACGTGAAGGCCATTGACATCTGGATGGCTGTTTGTCTGCTGTTCGTGTTTGCT

$$
\text { -...YCTKHYNTGKFTCIEVKFHLERQMGYYLIQMYIPSLLIVITS }
$$

FIGURE 8 | Morpholino oligonucleotides (SMO1 and SMO2) block splicing of glra4a. (A) Gross morphology of wild-type embryos and those injected with GlyR a4a translation-blocking (TMO) or splice site (SMO1 and SMO2) morpholinos. (B) Schematic of RT-PCR analysis of glra4a morpholinos confirmed the deletion of exon 7 for $\alpha 4 a-S M O 1$ (lane 3) and the deletion of part of exon 7 for a4a-SMO2 (lane 4). Intact GlyR $\alpha 4 a$ exon 7-9 PCR products are seen in the control (393 bp, lane 2) and smaller amounts are also observed in lanes 3 and 4 . A fragment of around 178 bp is seen in SMO1, which is made up of exon 6 and 8 only. A fragment of $321 \mathrm{bp}$ in SMO2 contains exons 6 and 8 and part of exon 7, which excludes the region that codes for TM2. GlyR $\alpha 1$ exon 7 is present in control and both SMO fish (lower panel). (C,D) DNA sequencing of GlyR $\alpha 4 a$ cDNAs from SMO1 and SMO2 treated fish reveals that SMO1 results in a 215 bp deletion, resulting in a frameshift and premature stop codon before $\mathrm{M} 1$, while SMO2 results in a 72 bp deletion and loss of 24 amino acids, including the majority of the pore-forming $\mathrm{M} 2$ domain 
production of EGFP. Therefore, areas within the zebrafish where EGFP is detected indicate cells where glra4a:GAL4 is normally expressed. EGFP expression directed by glra4a:GAL4 at $48 \mathrm{hpf}$ revealed that glra $4 a$ was predominantly expressed four clusters of hindbrain commissural neurons and selected spinal commissural interneurons (Figures 7B-D). The expression of glra4a:GAL4 in commissural primary and secondary ascending neurons of the spinal cord increased in intensity from $48 \mathrm{hpf}$ to $72 \mathrm{hpf}$ (Figures 7E,F). These spinal commissural neurones had two distinct morphologies: large soma with multidendritic processes and small soma with few dendrites. Interestingly, no motor neurons or other types of interneurons were labeled in this line.

\section{Morpholino Knockdown and Overexpression of an Artificial GlyR $\alpha 4 a$ R278Q Mutation Reveals Aberrant Swimming Behavior}

Splice site (SMO) and translation blocking (TMO) morpholinos $\alpha 4 \mathrm{a}-\mathrm{SMO} 1, \alpha 4 \mathrm{a}-\mathrm{SMO} 2$ and $\alpha 4 \mathrm{a}-\mathrm{TMO}$ were injected into zebrafish embryos. The morphology of the injected zebrafish was assessed at $48 \mathrm{hpf}$ (Figure 8A) and did not reveal any gross anatomical changes apart from slightly smaller eyes that were apparent in embryos injected with $\alpha 4 a-T M O$ and $\alpha 4 a-S M O 1$ (Figure 8A). Although it was not possible to monitor the efficacy of $\alpha 4 a-T M O$ knockdown, due to the lack of a specific
GlyR $\alpha 4$ a subunit antibody, RT-PCR was used to monitor the effects of $\alpha 4 \mathrm{a}-\mathrm{SMO} 1$ and $\alpha 4 \mathrm{a}-\mathrm{SMO} 2$. mRNA was extracted from zebrafish that had been injected with $\alpha 4 a-S M O 1$ and $\alpha 4 a-$ SMO2 plus non-injected zebrafish embryos (wild-type control). RT-PCR was performed using primers targeted within exon 6 (forward) and exon 8 (reverse) of zebrafish glra4a and the PCR products corresponding to exons 6-8 analyzed by agarose gel electrophoresis and DNA sequencing (Figure 8B). This analysis suggested that binding of $\alpha 4 \mathrm{a}-\mathrm{SMO} 1$ to the splice acceptor site resulted in skipping of exon 7 in a proportion of transcripts (note lower 178 bp band), whilst binding of $\alpha 4 a-S M O 2$ to the exon 7 acceptor site resulted in mis-splicing, so that a different "acceptor" site was used within exon 7. DNA sequencing of GlyR $\alpha 4$ a cDNAs from SMO1 and SMO2 treated fish revealed that SMO1 indeed resulted in exon 7 skipping (a 215 bp deletion) resulting in a frameshift and premature stop codon before M1. SMO2 results in usage of an exonic donor site, resulting in a $72 \mathrm{bp}$ deletion and loss of 24 amino acids, including the majority of the pore-forming M2 domain (Figure $8 \mathrm{C}$ ). By contrast, RT-PCR with similar primers targeted against zebrafish glral did not result in any aberrant splicing (Figure 8B, lower right panel) suggesting that the GlyR $\alpha 4$ a morpholinos used did not recognize this closely related target.

Wild-type zebrafish embryos respond to tactile stimulus with an "escape response" consisting of a C-bend, a counterturn, and a bout of rapid swimming (Figure 9A). However,

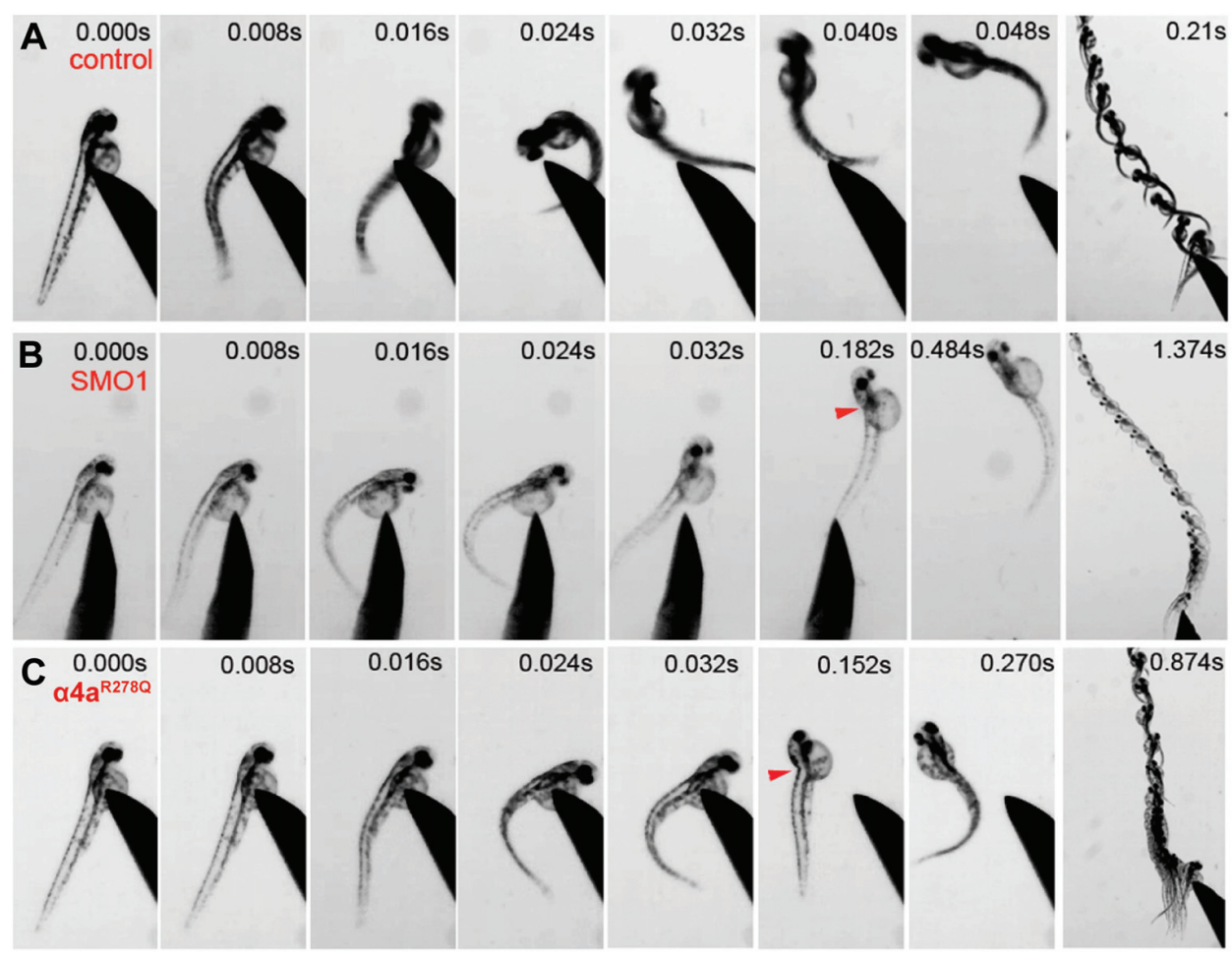

FIGURE 9 | Embryos injected with $\alpha 4 \mathrm{a}-\mathrm{SMO} 1$ and the $\alpha 4 \mathrm{a}^{\mathrm{R} 278 \mathrm{Q}}$ mutant embryos fail to exhibit correct escape behavior. (A) Wild-type (control) fish responds to touch by with a C-bend, a turn away from the stimulus and rapid swimming. However, embryos injected with $\alpha 4 a-S M O 1$ (B) or with mRNA for the GlyR $\alpha 4 \mathrm{a}^{\mathrm{R} 278 \mathrm{Q}}$ subunit (C) respond more slowly, and have a pronounced head retraction-similar to a localized beo-like contraction (arrow). Single images were extracted from high-speed movies of $\alpha 4 \mathrm{a}-\mathrm{SMO} 1$ morphants and embryos injected with GlyR $\alpha 4 \mathrm{a}^{\mathrm{R} 278 \mathrm{Q}}$ subunit mRNA. 
behavioral analysis of zebrafish embryos injected with $\alpha 4 a-$ SMO1 gave rise to transient spasms and prolonged head retraction (Figure 9B). $\alpha 4 \mathrm{a}-\mathrm{SMO} 1$ morphants did eventually recover and swim away from the stimulus, although this took longer than for wild-type zebrafish (Figures 9A,B). Thus, knockdown with $\alpha 4 \mathrm{a}-\mathrm{SMO} 1$ significantly impaired escape behavior. The same behavior was observed in embryos injected with in vitro-transcribed RNA for a GlyR $\alpha 4$ a subunit mutant harboring the R278Q mutation (Figure 9C; GlyR $\alpha 4 \mathrm{a}^{\mathrm{R} 278 \mathrm{Q}}$ ). This mutation is equivalent to the dominantly inherited startle disease mutation p.R271Q in the human GlyR $\alpha 1$ subunit (Shiang et al., 1993) that disrupts the link between agonist binding and channel gating without affecting cell-surface trafficking (Langosch et al., 1994; Chung et al., 2010). This suggests that the GlyR $\alpha 4 \mathrm{a}^{\mathrm{R} 278 \mathrm{Q}}$ dominant-negative mutant is able to incorporate into native zebrafish GlyRs and alter behavior in the same manner as morpholino knockdown by $\alpha 4 \mathrm{a}-\mathrm{SMO} 1$, resulting in aberrant tactile startle and escape responses.

\section{DISCUSSION}

The known biological roles of inhibitory GlyRs have expanded significantly in recent years, in part due to the range of mouse/zebrafish mutants and subtype-specific antibodies now available (Harvey et al., 2004; Hirata et al., 2010; Pilorge et al., 2016; Wilkins et al., 2016; Schaefer et al., 2017). However, GlyRs containing the $\alpha 4$ subunit have largely escaped scrutiny, largely because the human gene has an in-frame stop codon in exon 9, truncating the GlyR $\alpha 4$ subunit in the M4 domain. The GlyR $\alpha 4$ subunit gene is clearly intact and expressed in other organisms (e.g., Matzenbach et al., 1994; Harvey et al., 2000) and is even duplicated (GlyR $\alpha 4 \mathrm{a}$ and $\alpha 4 \mathrm{~b}$ ) in zebrafish (Imboden et al., 2001; Hirata et al., 2010). Given the recent implication of the human GlyR $\alpha 4$ subunit gene in human disease, we sought to: (1) Determine whether the human GlyR $\alpha 4$ subunit is indeed functional or can act in a dominant-negative manner; (2) To characterize the functional properties of $\alpha 4$-subunit GlyRs in artificial synapses; and (3) Determine the biological role of GlyR $\alpha 4$ using zebrafish as a model organism.

\section{The Human GlyR $\alpha \mathbf{4}$ Subunit Is Functionally Inactive Due to Multiple Damaging Changes}

Cloning and sequencing of human GlyR $\alpha 4$ subunit cDNAs (Figures 1, 2) demonstrated that GLRA4 is still transcribed and correctly spliced in human brain. However, no alternative splicing or RNA editing was observed that could "correct" the stop codon found at position 390. Functional expression of "wild-type" human GlyR $\alpha 4^{\mathrm{X} 390}$ did not result in functional GlyRs, although artificially-synthesized gorilla and chimpanzee $\alpha 4$ subunit cDNAs could direct the formation of functional GlyRs (Figure 3A). It was therefore surprising that mutagenesis of the stop codon in human GlyR $\alpha 4$ to a conserved arginine (p.X390R) did not restore function. Bioinformatics analysis using SIFT and PolyPhen-2 and further mutagenesis of the mouse and human GlyR $\alpha 4$ subunit cDNAs (Figures 3B,C) revealed that the human GlyR $\alpha 4$ subunit contains multiple damaging changes-including $\mathrm{K} 59 \mathrm{E}$ and $\mathrm{X} 390 \mathrm{R}$, and to a lesser extent C204Y and W421R - that inactivate human GlyR $\alpha 4$ subunit function. Restoration of multiple amino acids (K59E with either $\mathrm{C} 204 \mathrm{Y}$ or W421R) was required to restore function in the GlyR $\alpha 4^{\mathrm{R} 390}$ background. It is curious that either $\mathrm{C} 204 \mathrm{Y}$ or $\mathrm{W} 421 \mathrm{R}$ had an equivalent effect in restoring function given that: (1) these residues are not located near each other; and (2) incorporation of either residue together with K59E and $\mathrm{X} 390 \mathrm{R}$ results in $\alpha 4$ GlyRs with very high glycine sensitivity $\left(\mathrm{EC}_{50} \mathrm{~s}: \alpha 4^{\mathrm{K} 59 \mathrm{E} / \mathrm{X} 390 \mathrm{R} / \mathrm{W} 421 \mathrm{R}}: 7.6 \pm 1.3 \mu \mathrm{M} ; \alpha 4^{\mathrm{K} 59 \mathrm{E} / \mathrm{C} 204 \mathrm{Y} / \mathrm{X} 390 \mathrm{R}}\right.$ : $4.3 \pm 1.3 \mu \mathrm{M}$; Table 2 ). The similarly high glycine sensitivities of the human $\alpha 4^{\mathrm{K} 59 \mathrm{E} / \mathrm{C} 204 \mathrm{Y} / \mathrm{X} 390 \mathrm{R}}$ and $\alpha 4^{\mathrm{K} 59 \mathrm{E} / \mathrm{X} 390 \mathrm{R} / \mathrm{W} 421 \mathrm{R}}$ GlyRs are presumably caused by other residues that are not conserved between human and other species (e.g., L145, K170, I311). This finding also indicates that the individual C204 or W421 human residues do not completely impair GlyR function, which is supported by our mouse GlyR $\alpha 4$ mutagenesis study (Figure 3B) and the fact that we observed no deleterious effect of the gorilla GlyR $\alpha 4 \mathrm{Cys}^{204}$ residue in whole-cell patch-clamp experiments that compared mouse $\alpha 4$ and $\alpha 4 \beta$ GlyRs with gorilla $\alpha 4$ and $\alpha 4 \beta$ GlyRs (Figure 4). This in turn rules out the possibility that the loss of function in the $\alpha 4^{\mathrm{K} 59 \mathrm{E} / \mathrm{X} 390 \mathrm{R}} \mathrm{GlyR}$ is a cumulative effect of the two mildly "deleterious" endogenous residues (i.e., C204 and W421). Lastly, we also found that "wild-type" GlyR $\alpha 4^{\mathrm{X} 390}$ subunit was unable to act as a negative regulator of other GlyR subtypes (Figures 3D, 4). This was at first surprising, given that several elegant studies (Villmann et al., 2009; Haeger et al., 2010) have shown that truncated proteins containing the $\mathrm{N}$-terminal ligand-binding domain and first three transmembrane helices (M1-M3) of the GlyR $\alpha 1$ subunit can be rescued by co-expressing the fourth transmembrane domain (M4). However, additional artificial restoration of K59E/C204Y was required before co-assembly with the GlyR $\alpha 1$ subunit was observed. Hence, we consider it highly unlikely that the endogenous GlyR $\alpha 4$ subunit is involved in human disease by the mechanisms proposed by Labonne et al. (2016). Rather, sequence analysis of high coverage reads from the Denisovan genome (Reich et al., 2010) suggest that GLRA4 has been a pseudogene for at least 30,000-50,000 years.

\section{Unique Functional Properties of $\alpha 4$ Subunit GlyRs Revealed in Artificial Synapses and Outside-Out Patches}

Until this study, the functional properties of IPSCs mediated by $\alpha 4$-containing GlyRs had not been determined for any species. We therefore made whole-cell recordings from HEK293 cells expressing mouse or gorilla $\alpha 4$ and $\alpha 4 \beta$ GlyRs along with neuroligin 2 that had been co-cultured with spinal neurons. In this system, expression of GlyR $\alpha 1-3$ homomers typically results in robust IPSCs, with GlyR $\beta$ subunit incorporation accelerating IPSC rise and decay times for $\alpha 2 \beta$ and $\alpha 3 \beta$ heteromers. In addition, $\alpha 1 \beta$ and $\alpha 3 \beta$ GlyRs mediate fast decaying IPSCs, whereas $\alpha 2 \beta$ GlyRs mediate slow decaying IPSCs (Zhang Y. et al., 2015). In this study, we show that analysis of IPSCs (Figure 5) and analysis of IPSC $10 \%-90 \%$ rise times, decay time constants and amplitudes, revealed no significant differences 
between homomeric $\alpha 4$ and heteromeric $\alpha 4 \beta$-subunit mouse and gorilla GlyRs (Figure 5). IPSCs mediated by $\alpha 4$ or $\alpha 4 \beta$ GlyRs had a dramatically slower mean decay time constant ( $\sim 80 \mathrm{~ms}$; Figure 5C) than those mediated by either $\alpha 1 \beta, \alpha 2 \beta$ or $\alpha 3 \beta$ GlyRs (7.2, 25.7 and $9.7 \mathrm{~ms}$, respectively; Zhang Y. et al., 2015). Another unusual finding was that the intrinsic closing rate of the mouse $\alpha 4$ and $\alpha 4 \beta$ GlyRs in outside-out patches excised from HEK293 cells (Figure 6B) was much slower than the corresponding IPSC decay rate (Figure 5B). One possible explanation is that the synaptic clustering process imposes a conformational change upon $\alpha 4$-containing GlyRs that induces them to close at a faster rate. We were surprised to find that the $\alpha 4 \beta$ GlyR deactivation time constant was an order of magnitude slower than for the $\alpha 1 \beta$ GlyR (Scott et al., 2015; Zhang et al., 2016). We are not aware of any other pentameric ligand-gated ion channel that deactivates at such a slow rate. Taken together, these findings suggest that $\alpha 4$ subunitcontaining GlyRs have a unique physiological function and are possibly more suited to tonic rather than fast synaptic signaling.

\section{A Biological Role for GlyR $\alpha 4$ in Startle and Escape Responses}

In order to develop an in vivo model of GlyR $\alpha 4$ dysfunction, we utilized zebrafish, where an extended GlyR gene family $(\alpha 1$, $\alpha 2, \alpha 3, \alpha 4 a, \alpha 4 b, \beta a$ and $\beta b)$ presents many advantages for the study of receptor biology (Hirata et al., 2010, 2013; Ganser et al., 2013; Pilorge et al., 2016). Zebrafish also present other benefits in terms of the availability of artificial mutants and techniques for gene manipulation. For example, zebrafish bandoneon (beo) mutants harbor missense or nonsense mutations in glrbb that cause compromised glycinergic transmission and touchinduced bilateral muscle contractions (Hirata et al., 2005; Ganser et al., 2013). We have also previously demonstrated that GlyR gene-specific morpholinos can reveal distinct phenotypes in zebrafish larvae, such as embryonic spasticity (GlyR $\alpha 1$; Ganser et al., 2013) and axon-branching defects (GlyR $\alpha 2$; Pilorge et al., 2016). Zebrafish contain two GlyR a4 subunit genes, glra4a and glra $4 b$, with the expression of the latter gene being largely restricted to the retina (Imboden et al., 2001; Hensley et al., 2011). Using a novel Tol2-based gene-trap line, we detected glra4a expression in small interneuron populations in the hindbrain

\section{REFERENCES}

Acuña, M. A., Yévenes, G. E., Ralvenius, W. T., Benke, D., Di Lio, A., Lara, C. O., et al. (2016). Phosphorylation state-dependent modulation of spinal glycine receptors alleviates inflammatory pain. J. Clin. Invest. 126, 2547-2560. doi: $10.1172 /$ jci83817

Adzhubei, I., Jordan, D. M., and Sunyaev, S. R. (2013). Predicting functional effect of human missense mutations using PolyPhen-2. Curr. Protoc. Hum. Genet. Chapter 7:Unit7.20. doi: 10.1002/0471142905.hg0720s76

Aken, B. L., Achuthan, P., Akanni, W., Amode, M. R., Bernsdorff, F., Bhai, J., et al. (2017). Ensembl 2017. Nucleic Acids Res. 45, D635-D642. doi: 10.1093/nar/gkw1104

Avila, A., Vidal, P. M., Dear, T. N., Harvey, R. J., Rigo, J. M., and Nguyen, L. (2013). Glycine receptor $\alpha 2$ subunit activation promotes cortical interneuron migration. Cell Rep. 4, 738-750. doi: 10.1016/j.celrep.2013.07.016 and commissural primary and secondary ascending neurons of the spinal cord (Figure 7). We tested and validated multiple splice-site and translation blocking morpholinos (MOs) targeting glra4a using RT-PCR and DNA sequencing to show exon skipping and alternate acceptor site usage for exon 7 MOs resulting in truncation of zebrafish GlyR $\alpha 4 \mathrm{a}$ (Figure 8). High-speed video analysis of zebrafish embryos injected with $\alpha 4 \mathrm{a}$ splice site morpholino (SMO1) or a dominant-negative GlyR $\alpha 4 \mathrm{a}^{\mathrm{R} 278 \mathrm{Q}}$ subunit mutant gave rise to transient spasms and prolonged head retraction after a tactile stimulus (Figure 9). Thus, glra4a knockdown in zebrafish results in aberrant tactile escape responses, suggesting that at least in fish, GlyR $\alpha 4$ a helps to shape startle and escape responses. Given the known role of the spinal GlyR $\alpha 1 \beta$ subtype in startle disease in humans and animal models (Shiang et al., 1993; Ganser et al., 2013; Wilkins et al., 2016; Schaefer et al., 2017), a role for GlyR $\alpha 4$ in escape behaviors is not unexpected. However, one obvious area for future study is whether loss of GlyR $\alpha 4$ in humans has resulted in key differences in terms of startle and/or escape responses compared to other species.

\section{AUTHOR CONTRIBUTIONS}

$\mathrm{RJH}, \mathrm{MS}$ and JWL designed the experiments. KK generated the glra $4 a$ gene trap line. SL, PS, AB, VMJ, AK, MS, JWL and RJH performed the experiments. SL, PS, AB, VMJ, AK, JWL and RJH analyzed the data. RJH and JWL wrote the article. All authors were involved in revising the article for important intellectual content, and gave final approval of the version to be published.

\section{FUNDING}

This work was supported by Medical Research Council (G0500833, G0601585, J004049) to RJH; a Bloomsbury Colleges studentship to VMJ and RJH; Japan Society for the Promotion of Science (JSPS) KAKENHI (JP15H2370) and the National BioResource Project (NBRP) from the Japan Agency for Medical Research and Development (AMED) to KK; and the National Health and Medical Research Council of Australia (1058542) to JWL. The funders had no role in study design, data collection and analysis, decision to publish, or preparation of the manuscript.

Avila, A., Vidal, P. M., Tielens, S., Morelli, G., Laguesse, S., Harvey, R. J., et al. (2014). Glycine receptors control the generation of projection neurons in the developing cerebral cortex. Cell Death Differ. 21, 1696-1708. doi: 10.1038/cdd. 2014.75

Balansa, W., Islam, R., Fontaine, F., Piggott, A. M., Zhang, H., Xiao, X., et al. (2013). Sesterterpene glycinyl-lactams: a new class of glycine receptor modulator from Australian marine sponges of the genus Psammocinia. Org. Biomol. Chem. 11, 4695-4701. doi: 10.1039/c3ob40861b

Bar-Shira, O., Maor, R., and Chechik, G. (2015). Gene expression switching of receptor subunits in human brain development. PLoS Comput. Biol. 11:e1004559. doi: 10.1371/journal.pcbi.1004559

Blednov, Y. A., Benavidez, J. M., Black, M., Leiter, C. R., Osterndorff-Kahanek, E., and Harris, R. A. (2015). Glycine receptors containing $\alpha 2$ or $\alpha 3$ subunits regulate specific ethanol-mediated behaviors. J. Pharmacol. Exp. Ther. 353, 181-191. doi: 10.1124/jpet.114.221895 
Bode, A., Wood, S. E., Mullins, J. G., Keramidas, A., Cushion, T. D., Thomas, R. H., et al. (2013). New hyperekplexia mutations provide insight into glycine receptor assembly, trafficking, and activation mechanisms. J. Biol. Chem. 288, 33745-33759. doi: 10.1074/jbc.M113.509240

Boehm, S., Harvey, R. J., von Holst, A., Rohrer, H., and Betz, H. (1997). Glycine receptors in cultured chick sympathetic neurons are excitatory and trigger neurotransmitter release. J. Physiol. 504, 683-694. doi: 10.1111/j.1469-7793. 1997.683bd.x

Bormann, J., Hamill, O. P., and Sakmann, B. (1987). Mechanism of anion permeation through channels gated by glycine and $\gamma$-aminobutyric acid in mouse cultured spinal neurones. J. Physiol. 385, 243-286. doi: 10.1113/jphysiol. 1987.sp016493

Chung, S. K., Bode, A., Cushion, T. D., Thomas, R. H., Hunt, C., Wood, S. E., et al. (2013). GLRB is the third major gene of effect in hyperekplexia. Hum. Mol. Genet. 22, 927-940. doi: $10.1093 / \mathrm{hmg} / \mathrm{dds} 498$

Chung, S. K., Vanbellinghen, J. F., Mullins, J. G., Robinson, A., Hantke, J., Hammond, C. L., et al. (2010). Pathophysiological mechanisms of dominant and recessive GLRA1 mutations in hyperekplexia. J. Neurosci. 30, 9612-9620. doi: 10.1523/jneurosci.1763-10.2010

Deckert, J., Weber, H., Villmann, C., Lonsdorf, T. B., Richter, J., Andreatta, M., et al. (2017). GLRB allelic variation associated with agoraphobic cognitions, increased startle response and fear network activation: a potential neurogenetic pathway to panic disorder. Mol. Psychiatry 22, 1431-1439. doi: 10.1038/mp. 2017.2

Dixon, C., Sah, P., Lynch, J. W., and Keramidas, A. (2014). GABA $A_{\mathrm{A}}$ receptor $\alpha$ and $\gamma$ subunits shape synaptic currents via different mechanisms. J. Biol. Chem. 289, 5399-5411. doi: 10.1074/jbc.m113.514695

Dixon, C. L., Zhang, Y., and Lynch, J. W. (2015). Generation of functional inhibitory synapses incorporating defined combinations of $\mathrm{GABA}_{\mathrm{A}}$ or glycine receptor subunits. Front. Mol. Neurosci. 8:80. doi: 10.3389/fnmol.2015.00080

Dlugaiczyk, J., Hecker, D., Neubert, C., Buerbank, S., Campanelli, D., Becker, C. M., et al. (2016). Loss of glycine receptors containing the $\alpha 3$ subunit compromises auditory nerve activity, but not outer hair cell function. Hear. Res. 337, 25-34. doi: 10.1016/j.heares.2016.05.004

Du, J., Lü, W., Wu, S., Cheng, Y., and Gouaux, E. (2015). Glycine receptor mechanism elucidated by electron cryo-microscopy. Nature 526, 224-229. doi: $10.1038 /$ nature 14853

Fatima-Shad, K., and Barry, P. H. (1993). Anion permeation in GABA- and glycine-gated channels of mammalian cultured hippocampal neurons. Proc. Biol. Sci. 253, 69-75. doi: 10.1098/rspb.1993.0083

Ganser, L. R., Yan, Q., James, V. M., Kozol, R., Topf, M., Harvey, R. J., et al. (2013). Distinct phenotypes in zebrafish models of human startle disease. Neurobiol. Dis. 60, 139-151. doi: 10.1016/j.nbd.2013.09.002

Gilbert, D. F., Islam, R., Lynagh, T., Lynch, J. W., and Webb, T. I. (2009). High throughput techniques for discovering new glycine receptor modulators and their binding sites. Front. Mol. Neurosci. 2:17. doi: 10.3389/neuro.02.017.2009

Haeger, S., Kuzmin, D., Detro-Dassen, S., Lang, N., Kilb, M., Tsetlin, V., et al. (2010). An intramembrane aromatic network determines pentameric assembly of Cys-loop receptors. Nat. Struct. Mol. Biol. 17, 90-98. doi: 10.1038/nsmb.1721

Han, L., Talwar, S., Wang, Q., Shan, Q., and Lynch, J. W. (2013). Phosphorylation of $\alpha 3$ glycine receptors induces a conformational change in the glycine-binding site. ACS Chem. Neurosci. 4, 1361-1370. doi: 10.1021/cn400097j

Harvey, V. L., Caley, A., Müller, U. C., Harvey, R. J., and Dickenson, A. H. (2009). A selective role for $\alpha 3$ subunit glycine receptors in inflammatory pain. Front. Mol. Neurosci. 2:14. doi: 10.3389/neuro.02.014.2009

Harvey, R. J., Depner, U. B., Wässle, H., Ahmadi, S., Heindl, C., Reinold, H., et al. (2004). GlyR $\alpha 3$ : an essential target for spinal PGE $_{2}$-mediated inflammatory pain sensitization. Science 304, 884-887. doi: 10.1126/science.1094925

Harvey, R. J., Schmieden, V., Von Holst, A., Laube, B., Rohrer, H., and Betz, H. (2000). Glycine receptors containing the $\alpha 4$ subunit in the embryonic sympathetic nervous system, spinal cord and male genital ridge. Eur. J. Neurosci. 12, 994-1001. doi: 10.1046/j.1460-9568.2000.00993.x

Heinze, L., Harvey, R. J., Haverkamp, S., and Wässle, H. (2007). Diversity of glycine receptors in the mouse retina: localization of the $\alpha 4$ subunit. J. Comp. Neurol. 500, 693-707. doi: 10.1002/cne.21201

Hensley, M. R., Emran, F., Bonilla, S., Zhang, L., Zhong, W., Grosu, P., et al. (2011). Cellular expression of Smarca4 (Brg1)-regulated genes in zebrafish retinas. BMC Dev. Biol. 11:45. doi: 10.1186/1471-213x-11-45
Hirata, H., Carta, E., Yamanaka, I., Harvey, R. J., and Kuwada, J. Y. (2010). Defective glycinergic synaptic transmission in zebrafish motility mutants. Front. Mol. Neurosci. 2:26. doi: 10.3389/neuro.02.026.2009

Hirata, H., Ogino, K., Yamada, K., Leacock, S., and Harvey, R. J. (2013). Defective escape behavior in DEAH-box RNA helicase mutants improved by restoring glycine receptor expression. J. Neurosci. 33, 14638-14644. doi: 10.1523/JNEUROSCI.1157-13.2013

Hirata, H., Saint-Amant, L., Downes, G. B., Cui, W. W., Zhou, W., Granato, M., et al. (2005). Zebrafish bandoneon mutants display behavioral defects due to a mutation in the glycine receptor $\beta$-subunit. Proc. Natl. Acad. Sci. U S A 102, 8345-8350. doi: 10.1073/pnas.0500862102

Hösl, K., Reinold, H., Harvey, R. J., Müller, U., Narumiya, S., and Zeilhofer, H. U. (2006). Spinal prostaglandin $\mathrm{E}$ receptors of the $\mathrm{EP}_{2}$ subtype and the glycine receptor $\alpha 3$ subunit, which mediate central inflammatory hyperalgesia, do not contribute to pain after peripheral nerve injury or formalin injection. Pain 126, 46-53. doi: 10.1016/j.pain.2006.06.011

Huang, X., Shaffer, P. L., Ayube, S., Bregman, H., Chen, H., Lehto, S. G., et al. (2017). Crystal structures of human glycine receptor $\alpha 3$ bound to a novel class of analgesic potentiators. Nat. Struct. Mol. Biol. 24, 108-113. doi: $10.1038 / \mathrm{nsmb} .3329$

Imboden, M., Devignot, V., and Goblet, C. (2001). Phylogenetic relationships and chromosomal location of five distinct glycine receptor subunit genes in the teleost Danio rerio. Dev. Genes Evol. 211, 415-422. doi: 10.1007/s0042701 00164

Iossifov, I., O’Roak, B. J., Sanders, S. J., Ronemus, M., Krumm, N., Levy, D., et al. (2014). The contribution of de novo coding mutations to autism spectrum disorder. Nature 515, 216-221. doi: 10.1038/nature13908

James, V. M., Bode, A., Chung, S. K., Gill, J. L., Nielsen, M., Cowan, F. M., et al. (2013). Novel missense mutations in the glycine receptor $\beta$ subunit gene (GLRB) in startle disease. Neurobiol. Dis. 52, 137-149. doi: 10.1016/j.nbd.2012. 12.001

Johnson, G. D., Davidson, R. S., McNamee, K. C., Russell, G., Goodwin, D., and Holborow, E. J. (1982). Fading of immunofluorescence during microscopy: a study of the phenomenon and its remedy. J. Immunol. Methods 55, 231-242. doi: 10.1016/0022-1759(82)90035-7

Kawakami, K., Abe, G., Asada, T., Asakawa, K., Fukuda, R., Ito, A., et al. (2010). zTrap: zebrafish gene trap and enhancer trap database. BMC Dev. Biol. 10:105. doi: 10.1186/1471-213x-10-105

Kent, W. J., Sugnet, C. W., Furey, T. S., Roskin, K. M., Pringle, T. H., Zahler, A. M., et al. (2002). The human genome browser at UCSC. Genome Res. 12, 996-1006. doi: 10.1101/gr.229102

Keramidas, A., Moorhouse, A. J., Schofield, P. R., and Barry, P. H. (2004). Ligandgated ion channels: mechanisms underlying ion selectivity. Prog. Biophys. Mol. Biol. 86, 161-204. doi: 10.1016/j.pbiomolbio.2003.09.002

Kruger, W., Gilbert, D., Hawthorne, R., Hryciw, D. H., Frings, S., Poronnik, P., et al. (2005). A yellow fluorescent protein-based assay for high-throughput screening of glycine and $\mathrm{GABA}_{\mathrm{A}}$ receptor chloride channels. Neurosci. Lett. 380, 340-345. doi: 10.1016/j.neulet.2005.01.065

Kumar, P., Henikoff, S., and Ng, P. C. (2009). Predicting the effects of coding non-synonymous variants on protein function using the SIFT algorithm. Nat. Protoc. 4, 1073-1081. doi: 10.1038/nprot.2009.86

Labonne, J. D., Graves, T. D., Shen, Y., Jones, J. R., Kong, I. K., Layman, L. C., et al. (2016). A microdeletion at Xq22.2 implicates a glycine receptor GLRA4 involved in intellectual disability, behavioral problems and craniofacial anomalies. BMC Neurol. 16:132. doi: 10.1186/s12883-016$0642-\mathrm{z}$

Langosch, D., Laube, B., Rundström, N., Schmieden, V., Bormann, J., and Betz, H. (1994). Decreased agonist affinity and chloride conductance of mutant glycine receptors associated with human hereditary hyperekplexia. EMBO J. 13, $4223-4228$

Manzke, T., Niebert, M., Koch, U. R., Caley, A., Vogelgesang, S., Hülsmann, S., et al. (2010). Serotonin receptor 1A-modulated phosphorylation of glycine receptor $\alpha 3$ controls breathing in mice. J. Clin. Invest. 120, 4118-4128. doi: 10.1172/JCI43029

Matzenbach, B., Maulet, Y., Sefton, L., Courtier, B., Avner, P., Guénet, J. L., et al. (1994). Structural analysis of mouse glycine receptor $\alpha$ subunit genes. Identification and chromosomal localization of a novel variant. J. Biol. Chem. $269,2607-2612$. 
Meyer, G., Kirsch, J., Betz, H., and Langosch, D. (1995). Identification of a gephyrin binding motif on the glycine receptor $\beta$ subunit. Neuron $15,563-572$. doi: 10.1016/0896-6273(95)90145-0

Morelli, G., Avila, A., Ravanidis, S., Aourz, N., Neve, R. L., Smolders, I., et al. (2017). Cerebral cortical circuitry formation requires functional glycine receptors. Cereb. Cortex 27, 1863-1877. doi: 10.1093/cercor/bhw025

Nobles, R. D., Zhang, C., Müller, U., Betz, H., and McCall, M. A. (2012). Selective glycine receptor $\alpha 2$ subunit control of crossover inhibition between the on and off retinal pathways. J. Neurosci. 32, 3321-3332. doi: 10.1523/jneurosci.534111.2012

Pilorge, M., Fassier, C., Le Corronc, H., Potey, A., Bai, J., De Gois, S., et al. (2016). Genetic and functional analyses demonstrate a role for abnormal glycinergic signaling in autism. Mol. Psychiatry 21, 936-945. doi: 10.1038/mp.2015.139

Pinto, D., Pagnamenta, A. T., Klei, L., Anney, R., Merico, D., Regan, R., et al. (2010). Functional impact of global rare copy number variation in autism spectrum disorders. Nature 466, 368-372. doi: 10.1038/nature09146

Piton, A., Gauthier, J., Hamdan, F. F., Lafrenière, R. G., Yang, Y., Henrion, E., et al. (2011). Systematic resequencing of X-chromosome synaptic genes in autism spectrum disorder and schizophrenia. Mol. Psychiatry 16, 867-880. doi: $10.1038 / \mathrm{mp} .2010 .54$

Rees, M. I., Lewis, T. M., Kwok, J. B., Mortier, G. R., Govaert, P., Snell, R. G., et al. (2002). Hyperekplexia associated with compound heterozygote mutations in the $\beta$-subunit of the human inhibitory glycine receptor (GLRB). Hum. Mol. Genet. 11, 853-860. doi: 10.1093/hmg/11.7.853

Reich, D., Green, R. E., Kircher, M., Krause, J., Patterson, N., Durand, E. Y., et al. (2010). Genetic history of an archaic hominin group from denisova cave in Siberia. Nature 468, 1053-1060. doi: 10.1038/nature09710

Schaefer, N., Berger, A., van Brederode, J., Zheng, F., Zhang, Y., Leacock, S., et al. (2017). Disruption of a structurally important extracellular element in the glycine receptor leads to decreased synaptic integration and signaling resulting in severe startle disease. J. Neurosci. 37, 7948-7961. doi: 10.1523/jneurosci. 0009-17.2017

Scott, S., Lynch, J. W., and Keramidas, A. (2015). Correlating structural and energetic changes in glycine receptor activation. J. Biol. Chem. 290, 5621-5634. doi: 10.1074/jbc.m114.616573

Shiang, R., Ryan, S. G., Zhu, Y. Z., Hahn, A. F., O'Connell, P., and Wasmuth, J. J. (1993). Mutations in the $\alpha 1$ subunit of the inhibitory glycine receptor cause the dominant neurologic disorder, hyperekplexia. Nat. Genet. 5, 351-358. doi: 10.1038/ng1293-351

Simon, J., Wakimoto, H., Fujita, N., Lalande, M., and Barnard, E. A. (2004). Analysis of the set of $\mathrm{GABA}_{\mathrm{A}}$ receptor genes in the human genome. J. Biol. Chem. 279, 41422-41435. doi: 10.1074/jbc.M401354200

Stead, C., Brown, A., Adams, C., Nickolls, S. J., Young, G., Kammonen, J., et al. (2016). Identification of positive allosteric modulators of glycine receptors from a high-throughput screen using a fluorescent membrane potential assay. J. Biomol. Screen 21, 1042-1053. doi: 10.1177/1087057116657779
Tziridis, K., Buerbank, S., Eulenburg, V., Dlugaiczyk, J., and Schulze, H. (2017). Deficit in acoustic signal-in-noise detection in glycine receptor $\alpha 3$ subunit knockout mice. Eur. J. Neurosci. 45, 581-586. doi: 10.1111/ejn.13489

Villmann, C., Oertel, J., Ma-Högemeier, Z. L., Hollmann, M., Sprengel, R., Becker, K., et al. (2009). Functional complementation of Glra1 ${ }^{\text {spd-ot }}$, a glycine receptor subunit mutant, by independently expressed C-terminal domains. J. Neurosci. 29, 2440-2452. doi: 10.1523/jneurosci.440008.2009

Vogel, N., Kluck, C. J., Melzer, N., Schwarzinger, S., Breitinger, U., Seeber, S., et al. (2009). Mapping of disulfide bonds within the amino-terminal extracellular domain of the inhibitory glycine receptor. J. Biol. Chem. 284, 36128-36136. doi: 10.1074/jbc.m109.043448

Wilkins, M. E., Caley, A., Gielen, M. C., Harvey, R. J., and Smart, T. G. (2016). Murine startle mutant Nmf1laffects the structural stability of the glycine receptor and increases deactivation. J. Physiol. 594, 3589-3607. doi: $10.1113 /$ jp272122

Xiong, W., Cheng, K., Cui, T., Godlewski, G., Rice, K. C., Xu, Y., et al. (2011). Cannabinoid potentiation of glycine receptors contributes to cannabis-induced analgesia. Nat. Chem. Biol. 7, 296-303. doi: 10.1038/nchembio.552

Young, T. L., and Cepko, C. L. (2004). A role for ligand-gated ion channels in rod photoreceptor development. Neuron 41, 867-879. doi: 10.1016/s08966273(04)00141-2

Zhang, Y., Bode, A., Nguyen, B., Keramidas, A., and Lynch, J. W. (2016). Investigating the mechanism by which gain-of-function mutations to the $\alpha 1$ glycine receptor cause hyperekplexia. J. Biol. Chem. 291, 15332-15341. doi: 10.1074/jbc.M116.728592

Zhang, Y., Dixon, C. L., Keramidas, A., and Lynch, J. W. (2015). Functional reconstitution of glycinergic synapses incorporating defined glycine receptor subunit combinations. Neuropharmacology 89, 391-397. doi: 10.1016/j. neuropharm.2014.10.026

Zhang, C., Nobles, R. D., and McCall, M. A. (2015). GlyR $\alpha 2$, not GlyR $\alpha 3$, modulates the receptive field surround of off retinal ganglion cells. Vis. Neurosci. 32:E026. doi: 10.1017/S0952523815000280

Conflict of Interest Statement: The authors declare that the research was conducted in the absence of any commercial or financial relationships that could be construed as a potential conflict of interest.

Copyright (C) 2018 Leacock, Syed, James, Bode, Kawakami, Keramidas, Suster, Lynch and Harvey. This is an open-access article distributed under the terms of the Creative Commons Attribution License (CC BY). The use, distribution or reproduction in other forums is permitted, provided the original author(s) and the copyright owner are credited and that the original publication in this journal is cited, in accordance with accepted academic practice. No use, distribution or reproduction is permitted which does not comply with these terms. 